\title{
Recent Advances on Bacterial Cellulose-Based Wound Management: Promises and Challenges
}

\author{
Hedaiat Moradpoor $\left(\mathbb{D},{ }^{1}\right.$ Hossein Mohammadi $\left(\mathbb{D},{ }^{2}\right.$ Mohsen Safaei ${ }^{(D)},^{3}$ \\ Hamid Reza Mozaffari ${ }^{D},{ }^{4}$ Roohollah Sharifi ${ }^{D},{ }^{5}$ Pourya Gorji, ${ }^{6}$ Abu Bakar Sulong ${ }^{\mathbb{D}},{ }^{7}$ \\ Norhamidi Muhamad ${ }^{D},{ }^{7}$ and Mona Ebadi ${ }^{8}{ }^{8}$ \\ ${ }^{1}$ Department of Prosthodontics, School of Dentistry, Kermanshah University of Medical Sciences, Kermanshah, Iran \\ ${ }^{2}$ School of Mechanical Engineering, Faculty of Engineering, Universiti Teknologi Malaysia, 81310 UTM Johor Bahru, \\ Johor, Malaysia \\ ${ }^{3}$ Advanced Dental Sciences Research Center, School of Dentistry, Kermanshah University of Medical Sciences, Kermanshah, Iran \\ ${ }^{4}$ Department of Oral and Maxillofacial Medicine, School of Dentistry, Kermanshah University of Medical Sciences, \\ Kermanshah, Iran \\ ${ }^{5}$ Department of Endodontics, School of Dentistry, Kermanshah University of Medical Sciences, Kermanshah, Iran \\ ${ }^{6}$ Students Research Committee, Kermanshah University of Medical Sciences, Kermanshah, Iran \\ ${ }^{7}$ Department of Mechanical and Manufacturing Engineering, Faculty of Engineering and Built Environment, \\ Universiti Kebangsaan Malaysia, Bangi, 43600 Selangor Darul Ehsan, Malaysia \\ ${ }^{8}$ Institute of Advanced Technology (ITMA), Universiti Putra Malaysia (UPM), Serdang, Selangor 43300, Malaysia
}

Correspondence should be addressed to Mohsen Safaei; mohsen_safaei@yahoo.com

Received 27 October 2021; Revised 17 December 2021; Accepted 8 January 2022; Published 14 February 2022

Academic Editor: Qinglin Wu

Copyright (c) 2022 Hedaiat Moradpoor et al. This is an open access article distributed under the Creative Commons Attribution License, which permits unrestricted use, distribution, and reproduction in any medium, provided the original work is properly cited.

\begin{abstract}
Wound healing is a therapeutic challenge due to the complexity of the wound. Various wounds could cause severe physiological trauma and bring social and economic burdens to the patient. The conventional wound healing treatments using bandages and gauze are limited particularly due to their susceptibility to infection. Different types of wound dressing have developed in different physical forms such as sponges, hydrocolloids, films, membranes, and hydrogels. Each of these formulations possesses distinct characteristics making them appropriate for the treatment of a specific wound. In this review, the pathology and microbiology of wounds are introduced. Then, the most recent progress on bacterial cellulose- (BC-) based wound dressing discussed and highlighted their antibacterial and reepithelization properties in vitro and in vivo wound closure. Finally, the challenges and future perspectives on the development of BC-based wound dressing biomaterials are outlined.
\end{abstract}

\section{Introduction}

Due to the great advances in the treatment of many diseases in recent decades, the treatment of cancer, AIDS, autoimmune diseases, and microbial infections is still among the global challenges [1-4]. The skin functions as a barrier against the microbial invasion of the organs and regulates body temperature [5]. The science of wound healing dates back to 2200 B.C. during which wound cleaning, plaster sticking, and wound bandaging had been practiced. Nonetheless, the function of the skin can be compromised by surgical incisions and burns as well as illness (diabetes, cancer) [6]. In these circumstances, the structure of the skin needs to be immediately reestablished after skin injuries to keep the hemostasis of the body and prevent bacterial contamination [7].

Skin tissue infections are known as the common kinds of infections that affect 14 million people annually in the United States of America [8]. The statistics obtained from the United States of America reveal that there are 6.5 million 
patients with an annual treatment cost of $25 \$$ billion. The wounds resulting from trauma are the most incident ones which lead to almost 41 million emergency appointments. This condition imposes a cost of 670 billion $\$$ per year which includes healthcare and disability cases [9].

Thus, the development of wound dressing that actively contributes to the wound healing process and impedes bacterial invasion is crucial to reducing such a huge cost. The conventional wound healing treatments are bandage and gauze which possess several restrictions such as susceptibility to infection, nonbiodegradability, and secondary tissue damage. The available wound dressing in the market shows permeability and absorbability as well as adherence to the surface of the wound. However, they cause trauma and damage to the wound site upon removal [10].

The developed wound dressings up to now are comprised of films, sponges, and hydrogels from synthetic and natural materials, and their combination thereof exhibits distinct characteristics. The reproduction of the $3 \mathrm{D}$ extracellular matrix (ECM) of skin and efficient oxygen permeability is among the important characteristics of an ideal wound dressing. The natural polymers (biopolymer) are generally selected for wound treatment over synthetic counterparts due to their nontoxicity to the human body and being economical [11]. Thus, they were the topic of many researches in the medical field to find novel systems by which the complex hierarchical structure of natural tissues could be closely imitated [12]. Cellulose can be found in a wide range of living species, which is mainly harvested from cotton and trees. However, cellulose can be obtained from bacterial sources which were firstly reported in 1886 [13]. Bacterial cellulose (BC) is a natural polymer that is synthesized from bacterial sources. It reveals suitable biological biocompatibility and biodegradability and also possess unique physical and chemical properties of BC such as ultrafine nanofiber network, high crystallinity, high water retention capacity, and high tensile strength which make it suitable as a biomaterial for wound healing [14]. In recent years, a great effort has been made by the researchers to BC-based wound dressing biomaterial, and some review papers have been published and utilized as valuable sources on this particular topic [15-17]. However, the purpose of the present article is aimed at providing a literature review of the most recent progress on the topic of BC-based biomaterials as wound dressing for wound management in order to elucidate whether the BC represents an outdated or an open challenge for enhancing wound healing rate. In this review, after introducing the pathology and microbiology of wounds, the common characteristics of BC-based hydrogel discussed with particular focus on its in vitro and in vivo performance.

\section{Search Strategy}

Database Web of Science and PubMed were used for the bibliographic search. The electronic search was done since January 2011 until December 2021 to look for the papers related to bacterial cellulose as wound dressing biomaterials. The authors used the fowling search terms "Bacterial cellulose" OR wound dressing" OR "Skin tissue regeneration"
OR "wound healing." The following criteria were considered for this review paper: (1) English written papers, (2) original research articles and review papers, (3) clinical trials, and (4) in vivo and in vitro studies. A total number of 340 articles were retrieved. After the elimination of duplicate references, 168 references were selected for this review paper.

\section{Pathophysiology and Healing Process of the Wound}

The main protective barrier in the human body is the skin that has important functionalities such as controlling the temperature of the body and maintaining the waterelectrolyte balance [18]. When the cellular integrity is compromised or the tissue is disrupted, the physicomechanical or metabolism issues cause the wound to occur [19], and this disturbs the skin functionality. Wound recovery is a complex process since many factors including the type of wound (e.g., dry, acute, chronic, and exuding), and the health condition of the patient (e.g., anemia and diabetes) could affect wound healing.

The classification of skin wounds is either chronic or acute depending on the nature of the healing process and its duration. The burns and incisions cause an acute wound in which the healing tie is related to the number of skin layers and the skin size $[20,21]$. The wound is usually accompanied by the production of hypertrophic scar (HS) known as a fibroproliferative disorder.

Chronic wounds compromise the timely and orderly skin repair through a defective healing process [22]. There are four different categories of chronic wounds according to the Wound Healing Society: (1) pressure, (2) diabetic, (3) venous, and (4) arterial ulcer [23]. Five main phases are present in the healing process including (1) hemostasis, (2) inflammation, (3) migration, (4) proliferation, and (5) remodeling [24]. A cascade of synchronized events plays a role in the healing process including components of extracellular matrix (ECM) and soluble mediators as well as migrant and occupant cell populations [25]. In the hemostasis stage, the formation of fibrin clots impedes blood loss by vasoconstriction and contamination [26]. The inflammatory stage involves the recruitment of neutrophils, monocytes/ macrophages, and lymphocytes that are simultaneously started with hemostasis $[26,27]$. The inflammatory reactions are mainly characterized by irritation, edema (swelling), erythema (redness), pain, and itching [28].

The migration and proliferation stage are started with the migration of fibroblast to the wound site and differentiation into the myofibroblasts. This produces the components such as fibronectin, hyaluronic acid, collagen, and proteoglycan, which play a role to form ECM, new vascularization, and reepithelization [26]. The activity of myofibroblasts leads to a reduction in the wounded areas [29].

The final stage in the wound healing process is the remodeling in which all the previous activated stages are ceased [24]. It should be also noted that different stages of wound healing depend on the environmental $\mathrm{pH}$ value in the wound site. According to a previous study, the chronic wound possesses a $\mathrm{pH}$ value in the range of 7.15-8.9. For 
example, during the first phase of wound healing, the $\mathrm{pH}$ value of the wound site becomes acidic due to the invasion of cytokines, neutrophils, and macrophages. It has been reported that the alkaline $\mathrm{pH}$ value in the wound site can decrease the wound healing rate [30], while an acidic environment promoted the healing rate in the wound site [31]. In a study, the effects of different $\mathrm{pH}$ including acidic, neutral, and alkaline were investigated on the BCbased wound dressing in the cutaneous wound in vivo in Wistar rats, and acidic one showed the highest efficacy [32]. The percentage of healing is calculated by the following formula [33]:

$$
\begin{aligned}
& \text { Percentage of healing }(\%) \\
& =1-\frac{\text { Wound area on a partcular day }}{\text { Wound area on day zero }} \times 100 .
\end{aligned}
$$

The normal mechanism of wound healing could be interrupted by different factors which prolong the healing time [34]. For example, in the case of chronic wounds, severe physiological changes may happen to the wound, and this produces excessive exudates comprising of tissue-destroying proteases due to wound contamination [10]. Additionally, chronic wounds, burns, and diabetic ulcers have extended healing times. As an example, a high level of exudates is found in burn wounds, and this provides a favorable environment for bacterial growth [35]. The presence of these bacteria leads to wound inflammation through the expression of proinflammatory cytokines [36]. The extension of inflammation in the wound site impedes the formation of granule tissue due to a high content of metalloproteinase (MMP) degrading the components of ECM and as a consequence delay wound healing [37]. In addition, diabetic wounds show extended healing time due to the dry and keratinized characteristics. Thus, diabetic wounds are inclined to cutaneous infections [38].

\section{Bacterial Contamination of the Wound}

The bacteria naturally can colonize on both biological and nonbiological surfaces [39]. The colonization of microorganisms in patients with critical burn wounds can adversely affect the immune system and physically disrupt the skin barrier [40]. The open wound provides a favorable environment for bacterial colonization [41]. Open wounds are usually contaminated by the pathogen from the surrounding environment [42]. The Gram-positive organisms are predominant in the initial stage of chronic wound formation while the Gram-negative organisms present in the deep layer of skin, which leads to considerable tissue damage [8]. The bacterial infection is the most common clinical complication related to skin conditions, and it plays a key role in delaying the healing process [40]. Additionally, it causes a high rate of morbidity and mortality in the patients [43]. Thus, the skin functions need to be restored by immediate covering with wound dressings to impede contamination and promote skin healing [18]. For this purpose, natural and synthetic wound dressings with antibacterial properties have been developed in different forms such as sponge, hydrogel, films, and the membranes.

4.1. Role of Bacterial Microorganisms in Wound Healing. Upon the propagation of bacteria inside the wound, small chemical signals are produced which influence the immune cells and blood vessels. The immune cells further respond to these signals to kill the bacterial and suppress the spread of infection. For instance, the contact between the keratinocytes and the pathogenic microbes releases chemokines and cytokines initiating a defensive response. Consequently, reactive oxygen species (ROS) and antimicrobial peptides are produced which protect the skin layer from bacterial invasion.

The human skin is comprised of 1000 types of bacterial normal flora (skin microbiome). Although these bacteria are typically populated the human skin, however, they do not harm individuals (Figure 1) [44]. The commonly found bacterial normal flora is Proteobacteria, Firmicutes, and Bacteroidetes. Nonetheless, Staphylococcus epidermidis [45], Staphylococcus aureus [46], Staphylococcus haemolyticus, and Staphylococcus hominis [47] abundantly occupy the enormous skin space. It was reported that the skin barrier is retained by releasing phenol soluble modulins as well as bacteriocins from skin normal flora against harmful microbes [48].

The innate factors such as interleukin 1 (IL-1) and antimicrobial peptides are harmonized by the skin normal flora [49]. The synthesis of secretome by Staphylococcus epidermidis reduces the inflammation of the skin resulting from Staphylococcus aureus. This further activates the interleukin-10 (IL-10) by modulating with innate immunity [50]. It also increases the frequency of interleukin 17A (IL-17A) and interferon- $\gamma$ (IFN- $\gamma$ ) which leads to the enhancement of epidermal barrier and restriction of pathogen invasions. It was also reported that the exposure of wound injury to Staphylococcus epidermidis drastically enhance the reepithelialization and tissue granulation [51].

Moreover, the secretion and production of cathelicidins and human beta-defensin (Hbd-2) by epidermal keratinocytes and skin commensal organisms is induced by Staphylococcus epidermidis. This is followed by the activation of the Toll-like receptor (TLR-2) signaling pathway via the innate immune system. This response encourages wound healing by the suppression of pathogenic bacteria [52].

The pattern recognition receptor (PRP) is the other mechanism by which the skin normal flora restricts pathogen invasion. The nucleotide-binding oligomerization domain containing 2 (NOD2) is secreted and then bounds to the peptidoglycans of Gram-positive and Gram-negative bacteria [53]. This mechanism enables the skin commensals to recognize the potential pathogens and further eliminate them by triggering the innate immune system. The TLR-2 and NOD-2 specifically act as skin defenders and protect the skin from the invasion of Staphylococcus aureus. Comparably, the skin is protected against 


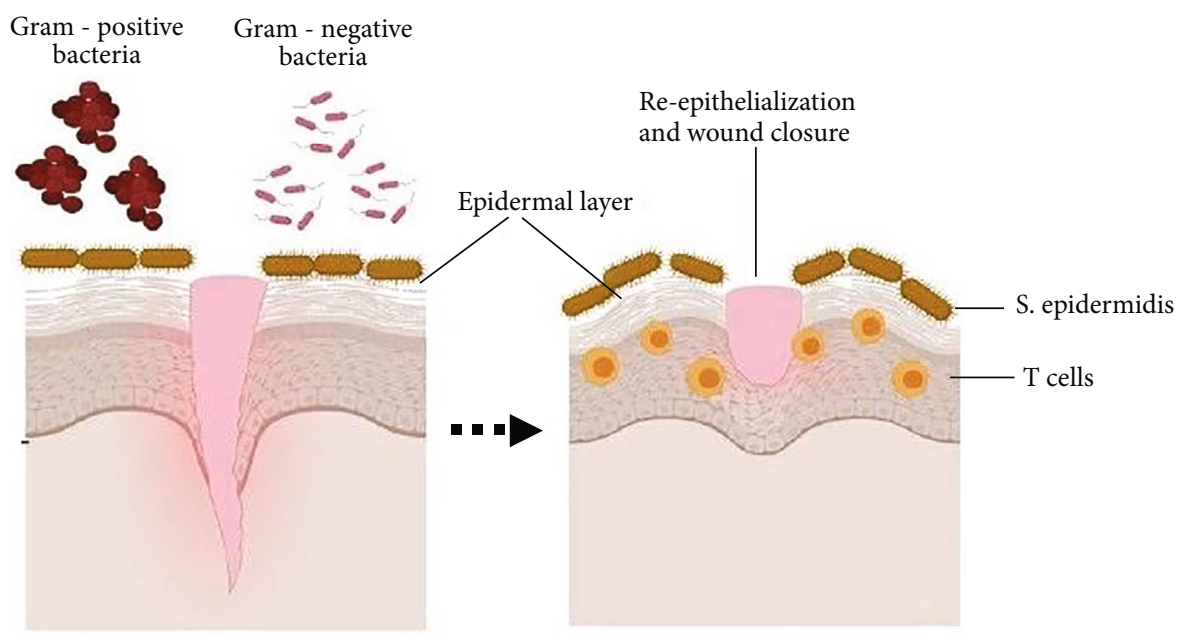

Figure 1: The role of Staphylococcus epidermidis on normal wound healing. As can be observed, it protects the skin from the invasion of bacteria by further preventing colonization by skin pathogens enhancing wound closure together with $\mathrm{T}$ cells, reprinted with permission [55].

infections such as papillomaviruses by TLR-7, TLR-8, and TLR-9 [54].

\section{Different Types of Dressing for Wound Management}

The wound dressings can be found in different physical forms such as film, membrane, sponge, fiber, and hydrogels. As already mentioned, the wound dressing biomaterials should accelerate and facilitate the wound healing process by protecting the wound from bacterial invasion, contamination, and the loss of moisture which compromise wound healing. Each of these forms exhibits distinct characteristics making them suitable to treat a particular type of wound. As an example, the sponges are highly porous and provide a moist environment at the site of the wound. However, their low mechanical properties cause maceration. Thus, they are not suitable for the treatment of third-degree burn wounds [56]. On the other hand, hydrocolloids are highly dense and nonadherent dressings. Additionally, they are painless and can be easily removed by sterilized water. Nonetheless, the maintenance of an acidic $\mathrm{pH}$ at the wound site, low mechanical properties, and toxicity restrict their application [57]. Films that are painless show impermeability to bacteria. Furthermore, the healing process can be monitored while using film wound dressing. However, their adherence to the wound bed leads to the accumulation of exudates, and they can be easily handled [21]. Consequently, the membrane membranes can act as a physical barrier. In addition, they show interconnected pores which facilitate reproducing the 3D architecture of ECM and control loss of fluid. Nonetheless, the solvents used during the production membrane are a major concern [58]. On the other hand, hydrogels possess high water storage capability inside their $3 \mathrm{D}$ polymeric network permitting them to provide a moist environment to the wound site. However, their low mechanical properties restrict their application [59].

\section{BC Polymeric Biomaterials}

6.1. General Properties. In recent years, the BC-based biomaterials have attracted attention for various applications such as wound dressing, dental implants applications due to their porous structure, nontoxicity, histocompatibility, and biocompatibility which have been reviewed elsewhere [60-65] The BC-based composite hydrogels for biomedical application have been reviewed elsewhere [66]. They have the flexibility to adapt the shape of the wound site, and in turn, reduce the possibility of bacterial infection through the prevention of direct contact between the wound and the external environment [67]. Also, the adsorption of exudate excess, antimicrobial activity, and low skin adherence can be modified in $\mathrm{BC}$ to meet the necessary functional requirements for wound healing applications [16]. The use of BC as wound dressing material was firstly reported in the 1980s by Farah and Ring works $[68,69]$. Also, the potential of BC as wound dressing material and artificial skin has been reported in the previous study [70]. The evaluation of skin tolerance of $\mathrm{BC}$ as wound dressing material revealed that BC films reduced inflammation and contributed to easy removal, suitable wound protection, and environment for cell proliferation in BALB/c mice in vivo compared to commercial Vaseline gauze and xenogeneic (pig and rat) and allogenic (mouse) skin grafts [71]. The positive effects of $\mathrm{BC}$ on the treatment of epidermis lesions have also been found in the literature $[72,73]$. The unique characteristics of BC including water-holding capability, high surface area, high porosity, high gas, and liquid permeability, and excellent tissue biocompatibility makes it suitable for wound dressing applications $[72,74]$. The molecular structure of hydrated BC and morphology of BC film is shown in Figure 2.

The fluid loss should be prevented in the burn wounds. Thus, the use of hydrophilic moisturizing dressing is suggested which adsorb the carrion on the wound, and this leads to the promotion of wound healing [75]. The water- 


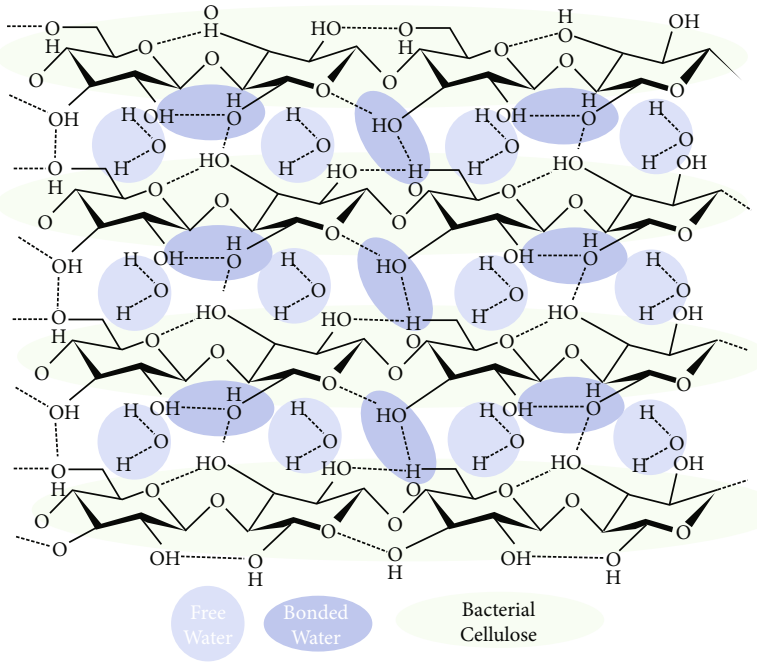

(a)

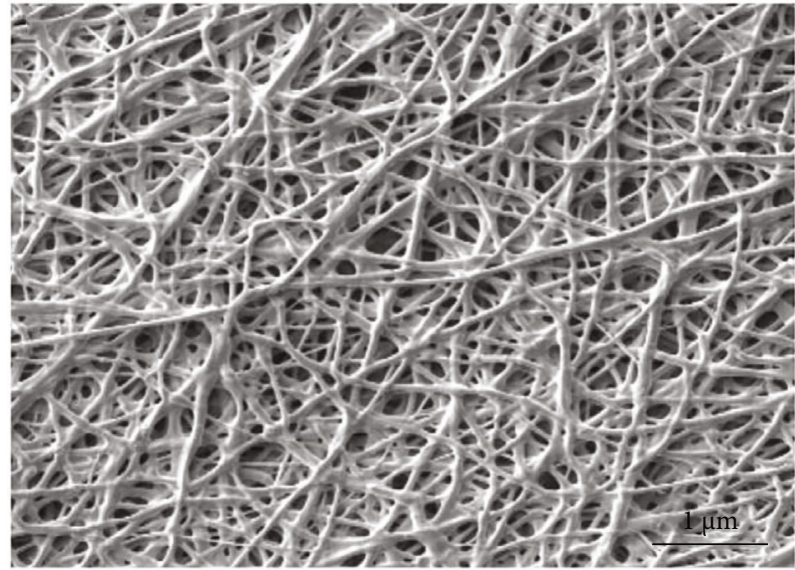

(b)

FIgURE 2: BC (a) molecular structure. (b) BC film morphology, reproduced with permission [17].

adsorbing capability and drying time of $\mathrm{BC}$ are $30 \%$ greater and $33 \%$ longer than that of cotton gauze, respectively [76]. The in vivo study has shown that BC wound dressings in porous form show better wound healing performance than the compacted form. This is ascribed to the insufficient pore size [77].

The cell recruitment, angiogenesis, and ECM remodeling are reduced in chronic wounds such as diabetic ulcers. Cavalcanti et al. have found that $\mathrm{BC}$ reduced the depth of ulcer in the lower limb, induced the remodeling of tissue, and started tissue granulation without any toxicity compared to limb without dressing in male patients [78]. The previous comparative study has shown that BC-based dressings shortened the time of wound healing in diabetic foot ulcers [79]. For example, Portal et al. have applied BC wound dressing in chronic wounds and found a faster healing rate compared to Dermafill ${ }^{\mathrm{TM}}$ commercial wound dressing. This was attributed to the better moist environment and faster epithelization [80]. Also, Silva et al. have reported the efficiency of $\mathrm{BC}$ gel and film in the treatment of chronic venous ulcers (CVU) stimulated reepithelization and significantly reduced the scar area [81].

In addition, the BC-based dressings showed better dermal burn treatment than silver sulfadiazine cream [82]. The BC-based dressings are more cost-effective in longterm clinical studies compared to conventional fiber dressings (surgical pads, tulle grass, and saline-soaked gas) as well as synthetic foams and alginate dressings [83].

The transparency of BC-wound dressing provides heat absorption and pain reduction making it suitable as a bandage for the patient with a burn wound [84]. The pain can be usually diminished by the proper control of moisture at the wound site. In other words, the capability to retain the humidity prevents the dehydration of wound dressing and in turn, its attachment to the wound. This ultimately diminished the pain by dressing exchange $[85,86]$.

The high surface area and porosity of BC make the incorporation of other compounds possible to accelerate wound healing $[74,87]$. In a study, macrophage-stimulating protein (MSP) was impregnated into $\mathrm{BC}$, this promoted the migration and proliferation of fibroblasts and collagen remodeling in the healing, and this effect was confirmed in vivo on burn wounds models of BALB-mice [77]. In another study, glycerin plasticizer was used to modify $\mathrm{BC}$, and the $\mathrm{BC} /$ glycerin composite showed excellent skin moisturizing in vivo [88]. A summary of BC properties and their effects on wound healing is shown in Table 1.

6.2. Biodegradation of $B C$. The biodegradation of biomaterials is of great importance for biomedical applications due to its effects on the functionality of biomaterials. The degradation alters the structural, chemical, and physical properties of the biomaterials. The biodegradability of biomaterials is determined by several parameters including temperature, time, and environmental conditions [93]. The biodegradation is known to be time-dependent which could be facilitated by biological activities [94]. Additionally, the body site that the biomaterial is exposed to also affects the biodegradation rate of biomaterials [95]. In addition, the degradation of polymeric biomaterials can also be triggered by external and internal stimuli as well as direct engineering [96]. The advantage of using biodegradable polymers is the extraction of degradation products from the body by the hydrolytic process via natural routes. Additionally, it causes no toxic effects and infection in the body [97]. Furthermore, the immune cells such as lymphocytes, monocytes, and neutrophils cause degradation resulting from the inflammatory response. Naturally, BC is nondegradable in the human body due to the lack of cellulose enzymes [98]. The biodegradation rate of $\mathrm{BC}$ could be affected by crystallinity, molecular weight, $\mathrm{pH}$, and chemical composition as well as water storage capability. It is worth noting that there should be a balance between the structural integrity and the functionality of BC-based biomaterials [99]. The possible mechanisms for BC degradation are (1) hydrolysis, (2) enzymatic, (3) oxidation, and (4) physical degradation [99]. In previous 
TABLE 1: BC properties for wound healing.

\begin{tabular}{lcc}
\hline Properties & Effects on wound healing & Ref. \\
\hline Biocompatibility and biodegradability & Low risk of fibrotic scaring avoidance of foreign body reaction & [89] \\
Mechanical stability and high permeability to gas and liquids & Protection from infection absorption of exudates & [90] \\
High capacity for liquid loading and flexibility & Efficient recovery easy removal avoidance of secondary injury & [91] \\
Hydrophilicity and water holding & Pain reduction provision of the moist environment & [92] \\
\hline
\end{tabular}

reports, it was found that BC-based wound dressing is gradually adsorbed and replaced by tissue during wound healing which formed a superficial skin layer [100-102].

\section{BC-Based Wound Dressing}

7.1. Water Holding Capacity. One of the key parameters in wound dressing materials, specifically in burn wounds, is water content and the water holding capacity, which keeps the wound hydrated and adsorbs exudates. As mentioned earlier, exudate removal is a decisive parameter determining the successful application of wound dressing. The reason is that it separates the tissue layers and in turn, slower the wound healing. Additionally, when the dehydration of wound dressing is avoided, then the attachment of wound dressing to the wound is impeded, and the moist environment accelerates the reepithelization and angiogenesis in the wound tissue [86]. The free unbounded water penetrating and exiting the $\mathrm{BC}$ molecular structure is responsible for the hydration level. The increase in healing rate, protection from infection, and pain reduction can be achieved by properly controlling the moisture [103]. Thus, a balance should be established between the liquid adsorption and release ensuring the maintenance of hydration during the healing process [104]. In this regard, the water holding capacity (WHC), water release rate (WRR), and water vapor transmission rate (WVTR) are important quantitative physical properties for the evaluation of dressing hydration. The high values of WVTR accelerate wound scabbing and dehydration while the low values of WVTR impede healing with a high risk of bacterial infection. According to a previous study, the WVTR in the range of $2500-3000 \mathrm{~g} / \mathrm{m}^{2} /$ day is desired [105]. Additionally, normal skin exhibits a WVTR value of $204 \mathrm{~g} / \mathrm{m}^{2} /$ day while injured skin shows a WVTR value ranging from 279 to $5138 \mathrm{~g} / \mathrm{m}^{2} /$ day [106].

In a study, Ag NP was incorporated into the carboxylated BC nanofibers (CNF), and the WVTR values were found to be $3431.59 \mathrm{~g} / \mathrm{m}^{2}$ per day and 2372.6 for $\mathrm{CNF}$ and Ag/CNF, respectively [107]. The high value of WVTR for CNF would lead to rapid dehydration of dressing and adhesion to the wound surface. By contrast, the Ag/CNF showed a suitable value of WVTR. In another study, the DOPA-coated BC with in situ reductions of Ag nanoparticles led to a decrease in WVTR value from $420 \mathrm{~g} / \mathrm{m}^{2} /$ day for $\mathrm{BC}$ to $400 \mathrm{~g} / \mathrm{m}^{2} /$ day. However, PD coating and Ag NP impregnation did not significantly affect the permeability of dressing and thus provided a proper WVTR to maintain a moist environment [108]. In another report, $\mathrm{ZnO}$ was incorporated into carboxyl BC membrane (BCM), and the composite membrane showed an average WVTR value of
$2856.60 \mathrm{~g} / \mathrm{m}^{2} /$ day which was considerably higher than that of $2506.56 \mathrm{~g} / \mathrm{m}^{2} /$ day for BCM [109]. In another report, $\mathrm{PHMB} / \mathrm{BC}$ composite membrane showed that the addition of PHMB significantly increased the WVTR compared to that of BC with a low WVTR. The WVTR value was found to be $2700 \mathrm{~g} / \mathrm{m}^{2} /$ day for the composite membrane which was higher than $1500 \mathrm{~g} / \mathrm{m}^{2} /$ day for $\mathrm{BC}$ that was suitable for wound treatment [100]. In a study, BC membrane, which carries chitosan on its surface, showed a WVTR value of $1460 \mathrm{~g} / \mathrm{m}^{2} /$ day, which was lower than that of $1503 \mathrm{~g} / \mathrm{m}^{2} /$ day for $\mathrm{BC}$ [110]. This revealed that both $\mathrm{BC}$ and $\mathrm{BC} /$ chitosan could maintain a moist environment for exudative wounds without excessive dehydration. This was ascribed to the presence of microfibril in those membranes. In another study, thymol was incorporated into the BC scaffold, and the results showed a slight decrease in the WVTR value of BC after thymol incorporation from 430 to $410 \mathrm{~g} / \mathrm{m}^{2} /$ day. However, a high WVTR value remained [111]. The reason for the decrease in WVTR value was the hydrophobic nature of thymol. In another study, the $\mathrm{P}(3 \mathrm{HB} / 4 \mathrm{HB}) / \mathrm{BC}$ composite dressing showed a WVTR value of $5014 \mathrm{~g} / \mathrm{m}^{2} /$ day which was significantly higher than that of $2655 \mathrm{~g} / \mathrm{m}^{2} /$ day for pure BC [102]. Mohamad et al. have grafted the acrylic acid onto BC hydrogel and found a WVTR value in the range of 2035$2666 \mathrm{~g} / \mathrm{m}^{2} /$ day which provided a desired level of moisture without dehydration [28].

Also, hydroxypropyltrimethyl ammonium chloride chitosan (HACC) and collagen-I (COL-I) were incorporated into the $\mathrm{BC}$ structure, and this multifunctional wound dressing exhibited a higher WVTR value of 3084 compared to 2819 for pure BC [112]. This could be attributed to the increased space between the polymeric chains promoting the water vapor diffusivity through the dressing. Chang et al. have shown that the addition of alginate and chitosan to BC film with higher water content increased the value of WVTR from $3034 \mathrm{~g} / \mathrm{m}^{2} /$ day to $3465 \mathrm{~g} / \mathrm{m}^{2} /$ day [113]. Ciecholewska-Juśko et al. have shown that the incorporation of hyaluronic acid (HA) into the BC hydrogel increased the water absorption capacity of BC. However, no value was presented for WVTR in their study [114]. Similarly, Kanjanamosit et al. have found an increase in water absorption capacity of BC membrane by increasing the alginate content due to the reduced porosity and increased density. Nonetheless, the WVTR value was decreased from $2100 \mathrm{~g} / \mathrm{m}^{2} /$ day to $1900 \mathrm{~g} / \mathrm{m}^{2} /$ day [115]. A summary of WVTR values of BCbased wound dressing is shown in Table 2.

7.2. Thermal Stability of BC. One of the key properties related to biomedical applications of BC is thermal stability. The thermal stability of polymeric biomaterials is defined as 
TABLE 2: WVTR values of BC-based wound dressing.

\begin{tabular}{lccc}
\hline Wound dressing & BC WVTR $\left(\mathrm{m}^{2} / \mathrm{g} /\right.$ day $)$ & Modified BC WVTR $\left(\mathrm{m}^{2} / \mathrm{g} /\right.$ day $)$ & Reference \\
\hline CNF/Ag NP & 3431.59 & 2372.6 & 400 \\
BC/DOPA & 420 & 2700 & {$[107]$} \\
PHMB/BC & 1500 & 2856.60 & {$[108]$} \\
BCM/ZnO & 2506.56 & 1503 & {$[109]$} \\
BC/chitosan & 1460 & 410 & {$[110]$} \\
BC/thymol & 430 & 5014 & {$[111]$} \\
P(3HB/4HB)/BC & 2655 & $2035-2666$ & 3084 \\
BC/AA & N/A & 3465 & {$[102]$} \\
BC/HACC/COL-I & $2819 \pm 47$ & 1900 & {$[112]$} \\
BC/chitosan/alginate & N/A & {$[113]$} \\
BC/alginate & 2100 & {$[115]$} \\
\hline
\end{tabular}

the ability of the polymer to withstand heat and retain its mechanical integrity in a certain temperature range [116]. The sterilization at high temperature is required for the biomaterial prior to use in the body. In addition, a hyperthermic condition is observed in severe wound burns due to the high inflammation. Thus, the wound dressing is needed to be thermally stable during which the body temperature varies [117].

The thermal stability of polymer can be affected by different parameters including molecular weight, crystallinity, and chemical structure [116]. The evaluation of thermal stability helps to understand the decomposition mechanism and clinical performance of BC in biomedical applications. The $\mathrm{BC}$ is degraded through exposure to either oxygen (oxidative degradation) or heat (thermal degradation) [116]. There are three different stages in the thermal degradation of BC: (1) the evaporation of water in the matrix, which occurs below $200^{\circ} \mathrm{C}$ leading to the rearrangement of molecular structure through disruption of intermolecular hydrogen bonds; (2) the obliteration of crystalline part, depolymerization of glycoside units, and decomposition of monomer occurring in the temperature range of $200^{\circ} \mathrm{C}-$ $400^{\circ} \mathrm{C}$ [118]; and (3) the breakdown of carbonaceous residues which occurs in the temperature above $400^{\circ} \mathrm{C}$ producing gaseous products with low molecular weight [119].

Generally, BC exhibits the weight loss in two stages: in the first stage, weight loss is occurred around $200^{\circ} \mathrm{C}$ due to water loss. Then, the significant weight loss is occurred in the second stage around $300^{\circ} \mathrm{C}$. This event also may be related to the degradation of cellulose, including the depolymerization, dehydration, and decomposition of glucose units. The difference could be attributed to the medium and source used for the preparation of BC. For example, the $\mathrm{BC}$ produced in the Hestrin-Schramm (HS) medium showed the decomposition temperature at $195^{\circ} \mathrm{C}$ while the $\mathrm{BC}$ produced in alternated HS medium (corn steep liquor) showed the decomposition temperature at $240^{\circ} \mathrm{C}$ [120].

The increase in thermal stability indicates that the weight loss is shifted to the higher temperatures. This finally leads to the shifting of degradation to the higher temperatures and reduction of weight loss. Mao et al. have found that an increase in the MXene content increased the thermal stability of rBC-based hydrogel [121]. The incorporation of collagen-I (COL-I) and hydroxypropyltrimethyl ammonium chloride chitosan (HACC) into BC exhibited a lower decomposition temperature of $300-383^{\circ} \mathrm{C}$ and $234-380^{\circ} \mathrm{C}$ than $310-410^{\circ} \mathrm{C}$ [112]. This was ascribed to the lower thermostability of COL-I and HACC decreased crystallinity of BC. Nonetheless, the simultaneous of HACC and COL-I into $\mathrm{BC}$ showed the thermal decomposition in the range of 310$400^{\circ} \mathrm{C}$ indicating the better thermal stability of HACC/ $\mathrm{COL}-\mathrm{I} / \mathrm{BC}$ wound dressing. The reason for this may be attributed to the intermolecular interactions between COLI, HACC, and BC. Also, gelatin was incorporated into BC and enhanced the thermal stability of wound dressing [122].

In contrast, Jiji et al. have reported that the impregnation of thymol decreased the decomposition temperature of $\mathrm{BC}$ from $366^{\circ} \mathrm{C}$ to $352^{\circ} \mathrm{C}$ [111]. Similarly, Caicedo et al. have shown a decrease in the decomposition temperature of $\mathrm{BC}$ from $330.7^{\circ} \mathrm{C}$ to $197.5^{\circ} \mathrm{C}$ [123]. Also, Pasaribu et al. have reported that the loading of microcolloidal Zanthoxylum acanthopodium (MZA) fruit was on BC fibers decreased the decomposition temperature from $357.8^{\circ} \mathrm{C}$ to $332.5^{\circ} \mathrm{C}$ [124]. Additionally, Keskin et al. have impregnated keratin into $\mathrm{BC}$, and this decreased the decomposition temperature from $353.58^{\circ} \mathrm{C}$ to $351.15^{\circ} \mathrm{C}$ showing lower thermal stability [125]. However, some reports have found that the modification of BC does not significantly alter the thermal decomposition temperature of BC. For example, Lamboni et al. have incorporated the silk sericin into the $\mathrm{BC}$ scaffold and showed a decomposition temperature in the range of $240-400^{\circ} \mathrm{C}$ which indicated that the incorporation of silk sericin did not significantly alter the thermal decomposition temperature of pure BC [126]. Similarly, Jiji et al. have modified $\mathrm{BC}$ with dopamine and Ag nanoparticles, and both pure and modified $\mathrm{BC}$ showed a similar decomposition temperature in the range of $320-400^{\circ} \mathrm{C}$ meaning that the $\mathrm{BC}$ modification did not alter the degradation temperature of the cellulose matrix [108]. Further, Khamraj et al. have reported that the modification of BC with dopamine and graphene oxide exhibited an initial thermal decomposition a little bit earlier at $250^{\circ} \mathrm{C}$ [127].

A summary of recent thermal stability related to BCbased wound dressing is shown in Table 3. It is clear that 
TABle 3: Thermal decomposition of the BC-based wound dressing.

\begin{tabular}{lccc}
\hline Wound dressing & BC temperature $\left({ }^{\circ} \mathrm{C}\right)$ & Modified BC temperature $\left({ }^{\circ} \mathrm{C}\right)$ & Reference \\
\hline BC/thymol & 366 & 352 & {$[111]$} \\
BC/DOPA & N/A & 350 & {$[127]$} \\
BC/DOPA/Ag & $320-400$ & 332.5 & {$[108]$} \\
BC/MZA & 357.8 & 351.15 & {$[124]$} \\
BC/keratin & 353.58 & 300 & {$[125]$} \\
BC/silk sericin & 300 & 351.56 & {$[126]$} \\
rBC/MXene & 343.33 & 197.5 & {$[123]$} \\
BC/chitosan & 330.7 & $310-400$ & {$[112]$} \\
BC/HACC/COL-I & $313-410$ & $310-420$ & {$[122]$} \\
BC/gelatin & $313-410$ & &
\end{tabular}

the type of reinforcing material such as thymol, silk sericin has an influence on the thermal stability of BC-based wound dressings.

\section{In Vitro and In Vivo Performance of BC-Based Wound Dressing}

The formation of granule tissue and proliferation of fibroblasts and keratinocytes are involved in the proliferative stage of wound healing. This may indicate the important role of fibroblasts and endothelial cells in retaining skin continuity. Volova et al. have loaded the fibroblast cells on the 3hydroxybutyric and 4-hydroxybutyric acids $\mathrm{P}(3 \mathrm{HB} / 4 \mathrm{HB}) /$ $\mathrm{BC}$ composite dressing film increased wound healing due to the promotion of epidermal epithelization [102].

Mohamad et al. have grafted AA onto BC, and the BC/ AA hydrogel promoted wound healing and improved fibroblast proliferation and epithelization in vivo in SpragueDawley rat [128]. Mohamad et al. have incorporated human epidermal keratinocytes (HEK) and human dermal fibroblasts (HDF) into BC/AA hydrogel, and this increased the healing rate and collagen deposition [75].

Moraes et al. have found that the incorporation of collagen into the BC membrane and showed higher wound healing performance with faster tissue regeneration in rat dorsal wound in vitro compared to that of commercial collagenous ointment [129]. The incorporation of HACC and CoL-I into BC was shown to support the proliferation and spread of NIH3T3 cells and HUVECs [112]. Tang et al. have incorporated hyaluronic acid (HA) into $\mathrm{BC}$ hydrogel and showed higher L9292 cell viability for BC/HA composite than BC which was attributed to the increased surface density and smoother surface [130].

Khan et al. have combined gelatin porogens with microporous regenerated bacterial cellulose ( $\mathrm{rBC}$ ), and the rBC/gelatin showed better wound closure and healing around $60 \%$ compared to that of $\mathrm{BC}$ alone in vivo in C57BL/6 mice (dorsal flank skin) and supported the adhesion and proliferation of human keratinocyte cells ( $\mathrm{HaCaT})$ compared to never-dried BC (ND-BC) [131]. Kingkaew et al. have impregnated chitosan into $\mathrm{BC}$, and the $\mathrm{BC} /$ chitosan composite film showed antibacterial properties and pro-

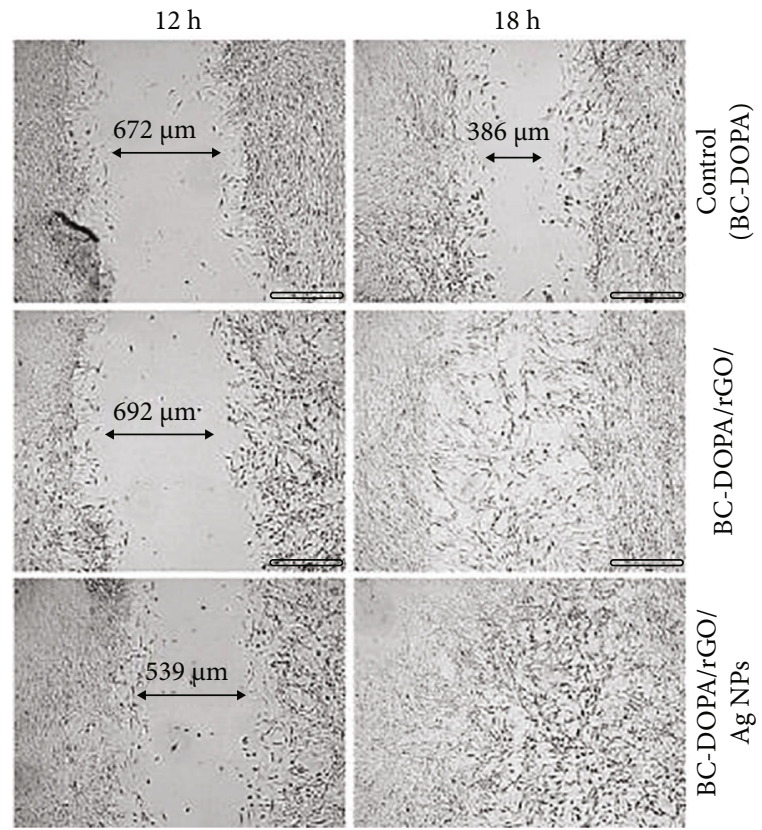

FIGURE 3: Images of the wound-healing activity over the NIH 3T3 cell line after 12 and $18 \mathrm{~h}$ for $\mathrm{BC} /$ dopamine, BC/dopamine/rGO, $\mathrm{BC} /$ dopamine/rGO, and $\mathrm{Ag} \mathrm{NP}$, respectively, reproduced with permission [127].

moted the skin keratinocytes and fibroblasts at different concentrations of chitosan [132]. Li et al. have incorporated hyaluronan (HA) into $\mathrm{BC}$, and the $\mathrm{BC} / \mathrm{HA}$ composite film shortened the healing time and showed significant tissue repair in vivo in Wistar rats [133].

Keskin et al. also have the impregnated keratin into BC, and the results showed an enhanced attachment of keratinocytes and fibroblasts on the composite dressing [125]. Radu et al. have incorporated keratin into BCM, and the keratin/ BCM demonstrated the potential regenerative potential in vivo in the dorsal burned wounds in rabbits [134]. Lin et al. have incorporated dextran in BC hydrogel and showed accelerated wound healing in C57BL/6 mice in vivo compared wet BC commercial dressing and dried-film Tegaderm [135]. 


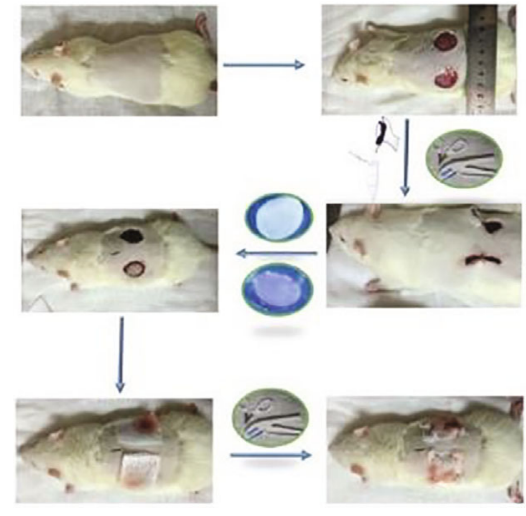

(a)

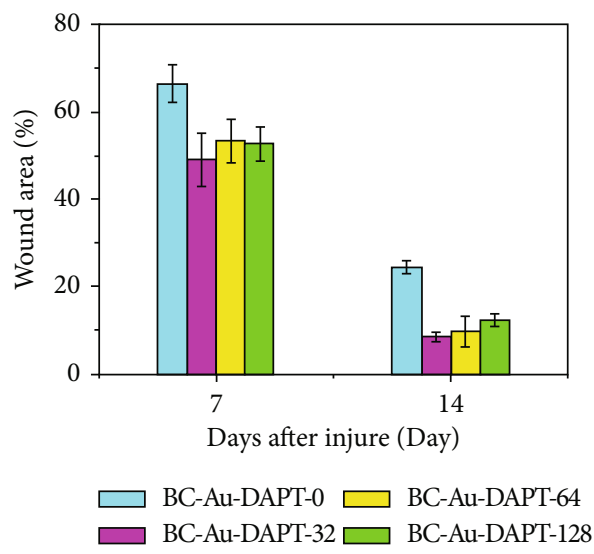

(c)

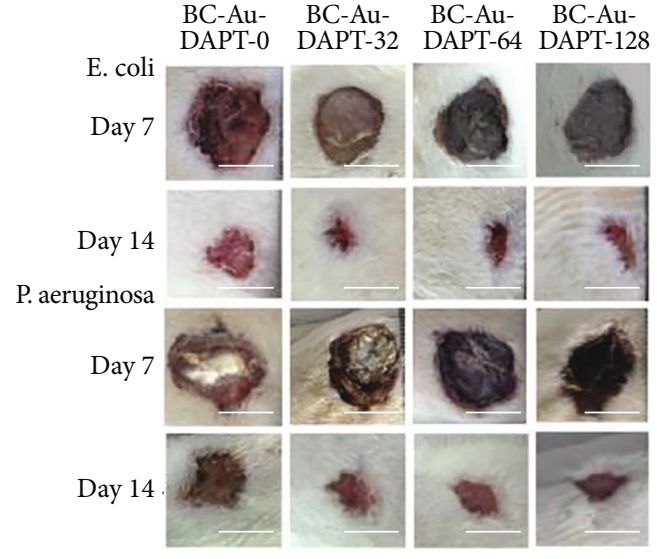

(b)

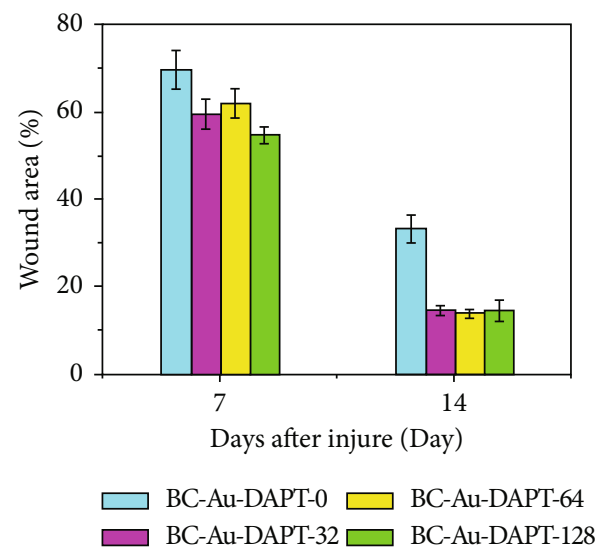

(d)

FIGURE 4: Generation of the bacterially infected wound on rat mode: (a) established infected wound and (b) the wound healing under treatment of BC and BC-Au-DAPT nanocomposites. The bacterially infected wound on the rat model after 7 and 14 days and (c) wound area in E. coli-infected wound and (d) wound area in P. aeruginosa-infected wound, reprinted with permission [168].

Qiao et al. have incorporated the arginine into microporous bacterial cellulose (MOBC) and showed the direct participation of $\mathrm{BC} /$ arginine into wound healing through increasing the migration and proliferation of fibroblasts and keratinocytes [136]. Farideh et al. have incorporated arginine into the BC-based nanofibers (BC-NF), and they showed promoted wound closure and faster healing rate for Arg/BCNF compared to BCNF alone. This was ascribed to better reepithelization and angiogenesis [137]. Qiao et al. have grafted arginine with microporous oxidized BC $(\mathrm{MOBC})$, and this increased the proliferation and migration of fibroblast and endothelial cells [136]. Nonetheless, further in vivo investigation needs to be conducted.

Lin et al. have incorporated dextran into $\mathrm{BC}$ and $\mathrm{BC} /$ dextran hydrogel-induced fibroblast cell proliferation and accelerated wound healing compared to wet BC [135]. Lamboni et al. have incorporated silk sericin (SS) into the $\mathrm{BC}$, and the BC/SS composite showed accelerated fibroblast cell proliferation and wound healing [126]. Lin et al. have incorporated dextran in $\mathrm{BC}$ hydrogel and showed accelerated wound healing in C57BL/6 mice in vivo compared wet $\mathrm{BC}$ commercial dressing and dried-film Tegaderm [135].

\section{New Strategies to Enhance the Performance of BC-Based Wound Dressing}

9.1. Incorporation of Mesenchymal Stem Cells. The recent strategy to enhance the $\mathrm{BC}$ properties for better wound healing is the incorporation of mesenchymal stem cells (MSCs) into the $\mathrm{BC}$ structure. It is expected that the cells integrate with host skin tissue and improve the regeneration and repair of injured tissue. In this regard, Loh et al. have incorporated $\mathrm{AA}$ into $\mathrm{BC}$, and then the $\mathrm{BC} / \mathrm{AA}$ hydrogel was loaded with human epidermal keratinocytes (HEK) and human dermal fibroblast (HDF). The BC/AA cell carrier showed higher wound healing performance in athymic mice in vivo with subsided blood vessels compared with BC scaffold alone [101]. Souza et al. have seeded adipose mesenchymal stem cells (AMSCs) on never-dried bacterial cellulose (ND-BC) membrane in the presence of fluconazole showed highly-regenerative potential to treat burn wounds in vivo in Wistar rat wound [138]. Silva et al. have incorporated rabbit bone marrow mesenchymal stem cells (rBMSCs) into the $\mathrm{BC}$ membrane, and the results revealed good biocompatibility [139]. Cao et al. have human urine-derived stem cells (hUSCs) on bacterial cellulose membrane (BCM), and the 
results showed a faster healing rate in vivo in SpragueDawley rate skin wound. This faster healing rate was ascribed to better angiogenesis in the wound site [140]. Mohamad et al. have incorporated AA into BC hydrogel and then loaded it with human epidermal keratinocytes (HEK) and human dermal fibroblast (HDF). The results showed an increased wound healing in burn wounds in athymic mice in vivo than BC/AA alone [75].

9.2. Immobilization of Growth Factors. The other strategy to enhance the performance of $\mathrm{BC}$-based wound dressing is the immobilization of growth factors. The growth factors that are produced by the cells play an important role in wound healing mechanisms by the stimulation of angiogenesis and cellular proliferation affecting the fibroblast activity [10] and accelerating the recovery of complex wounds [141]. Lin et al. have immobilized basic fibroblast growth factor (bFGF), human epidermal growth factor (hEGF), and keratinocyte growth factor (KGF) on macroporous BC hydrogel, and these $\mathrm{BC} /$ growth factors supported the growth of skin fibroblast [142]. Wang et al. have loaded vascular endothelial growth factor (VEGF) on the heparinized BC/gelatin scaffold, and the results showed effective angiogenesis in comparison with BC/gelatin alone in an ex ovo model [143]. This was ascribed to the sustained delivery of VEGF.

9.3. Nano- and Micropatterning. It has been reported that the micro- and nanoscale surface morphology of ECM provides the physical signals affecting cell interactions [144]. In addition, the distribution and the ultimate architecture of collagen have involved the formation of scars. Therefore, scar-free wound healing can be achieved through the manipulation of cell migration and orientation in the ECM remodeling [145]. In this regard, Jin et al. have patterned BC with stripes of $10 \mu \mathrm{m}$, and this significantly reduced the scar size and impeded the inflammatory response in vivo in $\mathrm{BALB} / \mathrm{c}$ mice compared to nanopatterned $\mathrm{BC}$ and petrolatum gauze [146]. This reduction in scar size was due to the decrease in fibroblast accumulation. Also, $\mathrm{Hu}$ et al. have modified the surface of porous micropatterned $\mathrm{BC}$ by arginine-glycine-aspartate-serine (RGDS-MPBC), and this guided the ordering of human skin fibroblasts (HSF) on the surface and formed dense collagen leading to a better healing effect compared to petrolatum gauze [147]. The insufficient porosity and the control on the internal structure can restrict the 3D cell proliferation and in turn and decrease the efficiency of wound dressing biomaterials. Yu et al. have shown that the hollow $\mathrm{BC}$ microsphere showed a faster wound healing in vivo in Sprague-Dawley rat compared to both $\mathrm{BC}$ microsphere and bulk BC membrane [148]. This could be ascribed to the increase in porosity and water retention capability.

9.4. Combined Therapies of $B C$ and Irradiation. The combination of phototherapy and wound dressing can lead to the acceleration of the wound healing process [149]. In this regard, Mohamad et al. have grafted AA onto BC hydrogel under electron beam irradiation, and BC/AA hydrogel showed in vivo biocompatibility in guinea pigs and proved to be nonirritant and nonallergic [28]. Additionally, they

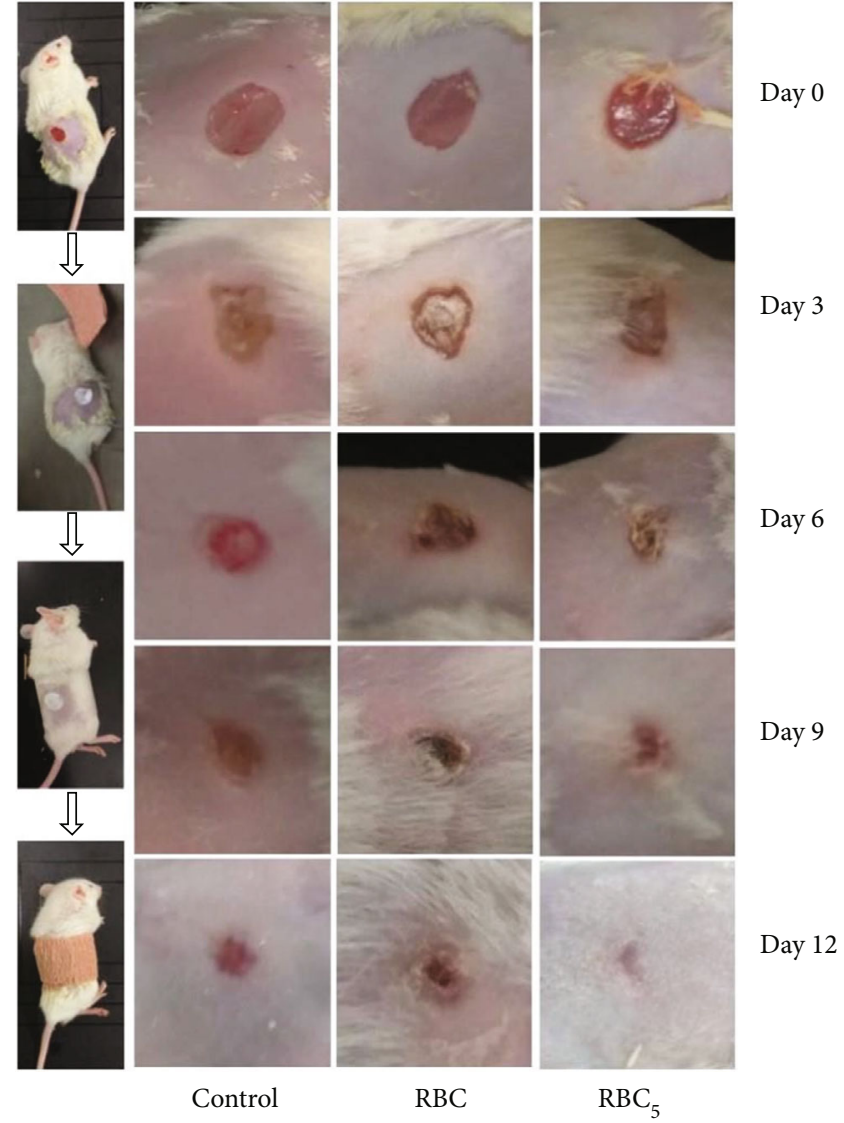

FIgURE 5: In vivo wound healing of RBC and amoxicillin grafted $\mathrm{RBC}\left(\mathrm{RBC}_{5}\right)$ after 12 days. Both $\mathrm{RBC}$ and amoxicillin-grafted $\mathrm{RBC}$ improved wound healing, and $\mathrm{RBC}_{5}$ revealed a faster wound healing rate compared to RBC, reprinted with permission [169].

have shown that the dose of irradiation can significantly affect the physicochemical properties of the wound dressing in which its adhesiveness was reduced. Also, Pandey et al. have grafted $\mathrm{AA}$ onto $\mathrm{BC}$ by microwave irradiation, the $\mathrm{BC} / \mathrm{AA}$ hydrogel showed faster healing and wound closure rate than $\mathrm{BC}$ with no sign of inflammatory response in vivo in the Sprague-Dawley rat, and this was attributed to the accelerated reepithelization resulting from the moist environment [150]. Further, Brassolatti et al. have applied the photobiomodulation (PBM) on the $\mathrm{BC}$ membrane, they found better in vivo wound healing in Wistar rats with third-degree wound, and this was attributed to the lower inflammatory response and higher vessel formation but it was lower than the BC alone [151].

\section{BC-Based Wound Dressing as the Drug Delivery System}

The BC-based wound dressing can also act as a drug delivery system (DDS) in which different dugs and macromolecules are loaded. Generally, high surface area and the presence of hydroxyl groups capable of intermolecular and chemical interactions facilitate the incorporation of large biomacromolecules and nanoparticles $[152,153]$. The microporosity 


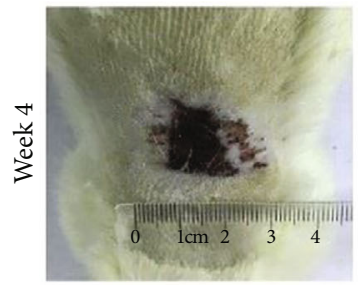

Control

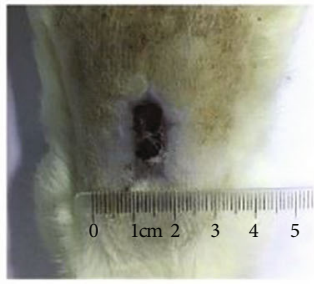

Biofill $^{\circledR}$

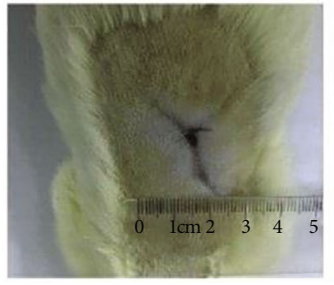

Biatain ${ }^{\circledR}$

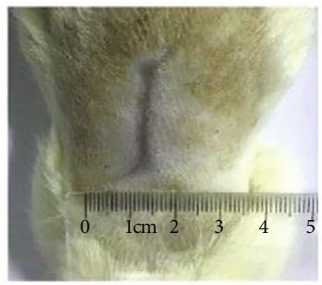

PHMB-PBC-2

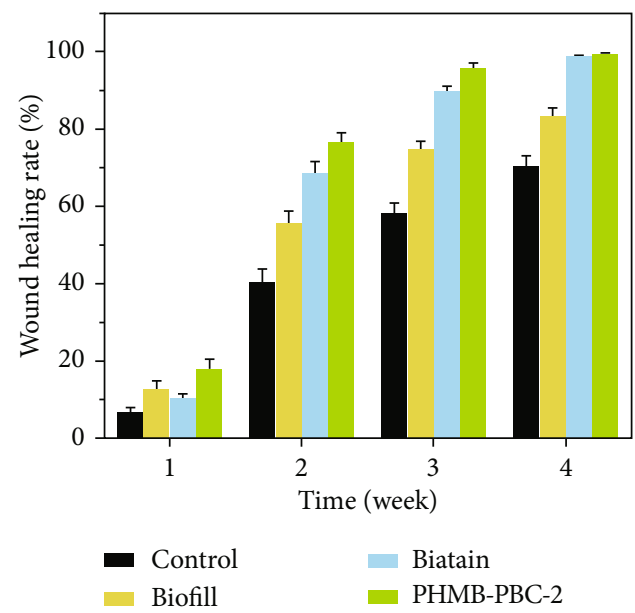

Figure 6: Macroscopic observation skin wound treated with different wound dressing materials: Biofill ${ }^{\circledR}$, Biatain $^{\circledR}$, and PHMB-PBC-2 after 4 weeks, reproduced with permission [100].

of BC structure provides slow drug release into the colonized wound with long-lasting antibacterial activity against bacterial growth [154]. However, they should not disrupt the normal wound healing process [155].

The BC intrinsic characteristic is not enough to meet the requirement in dressing materials. The $\mathrm{BC}$ acts as a physical barrier against bacterial invention and lacks antibacterial properties to impede bacterial infection itself $[72,156]$. This decreases the efficiency of BC in treating highly contaminated wounds. As DDS, the efficacy of $\mathrm{BC}$ can be enhanced by using the water uptake to load BC with antimicrobial agents such as antibiotics [157]. For this purpose, anti-inflammatory and antimicrobial drugs such as diclofenac and ibuprofen [158], antibacterial nanomaterials such as silver $\left(\mathrm{Ag}^{+}\right)$, zinc oxide $(\mathrm{ZnO})$, graphene oxide (GO), and titanium oxide $\left(\mathrm{TiO}_{2}\right)$, and specific polymers are commonly incorporated into the BC-based wound dressing $[74,159,160]$.

10.1. Antibacterial Nanomaterials. Various antibacterial nanomaterials have been incorporated into BC wound dressing to improve its efficiency. The $\mathrm{BC} / \mathrm{ZnO}$ composite was found to have better antibacterial properties and cell adhesion compared to pure $\mathrm{BC}$ [161]. Also, the $\mathrm{BC} / \mathrm{ZnO}$ scaffold revealed significant healing performance and tissue regeneration in the burn mic model in vivo in Balb mice than that of the pure BC dressing scaffold [33]. This was due to the antibacterial properties of $\mathrm{Zn}$ and its positive effect on the proliferation of keratinocytes. The $\mathrm{ZnO} /$ carboxyl $\mathrm{BC}$ membrane
(BCM) significantly shortened the wound closure, decreased the inflammatory response in vivo in $\mathrm{BalB} / \mathrm{C}$ mice, and was found to be nonirritant to the skin in vivo in the dorsal skin of New Zealand white rabbit [109]. This was ascribed to antibacterial properties, which accelerates the reepithelization and wound contraction.

The $\mathrm{TiO}_{2} / \mathrm{BC}$ enhanced the proliferation of MC3T3-E1 and antibacterial properties than $\mathrm{BC}$ as previously reported [162]. Further, $\mathrm{TiO}_{2} / \mathrm{BC}$ was found to accelerate the in vivo wound healing performance and reepithelization in mice burn wound models [163]. Additionally, functionalization of BC with carbon quantum dots-titanium dioxide $\left(\mathrm{CQD}-\mathrm{TiO}_{2}\right)$ demonstrated a more effective in vitro wound healing in L929 fibroblast cells than BC using scratch test [164]. This was ascribed antibacterial properties of $\mathrm{Ti}$ and its involvement in the acceleration of cell proliferation and formation of vascular tissue.

The Ag/carboxylated BC nanofibers (CNF) showed effective wound healing in vivo in Kunming mice. This was ascribed to the antibacterial and hemostatic properties in wound beds. However, hemostatic properties were slightly decreased due to the presence of Ag [107]. The BC/Ag membrane showed a greater healing rate than that of pure $\mathrm{BC}$ in vivo in Wistar rats [165]. Furthermore, BC/Ag membrane enhanced wound healing in vivo in rats with second-degree wound mode [166]. This was due to the reduction of bacteria and inflammation in the wound. The DOPA-modified BC-GO-Ag accelerated in vitro wound healing (scratch and heal) over NIH3-T3 fibroblast and A549 human lung 


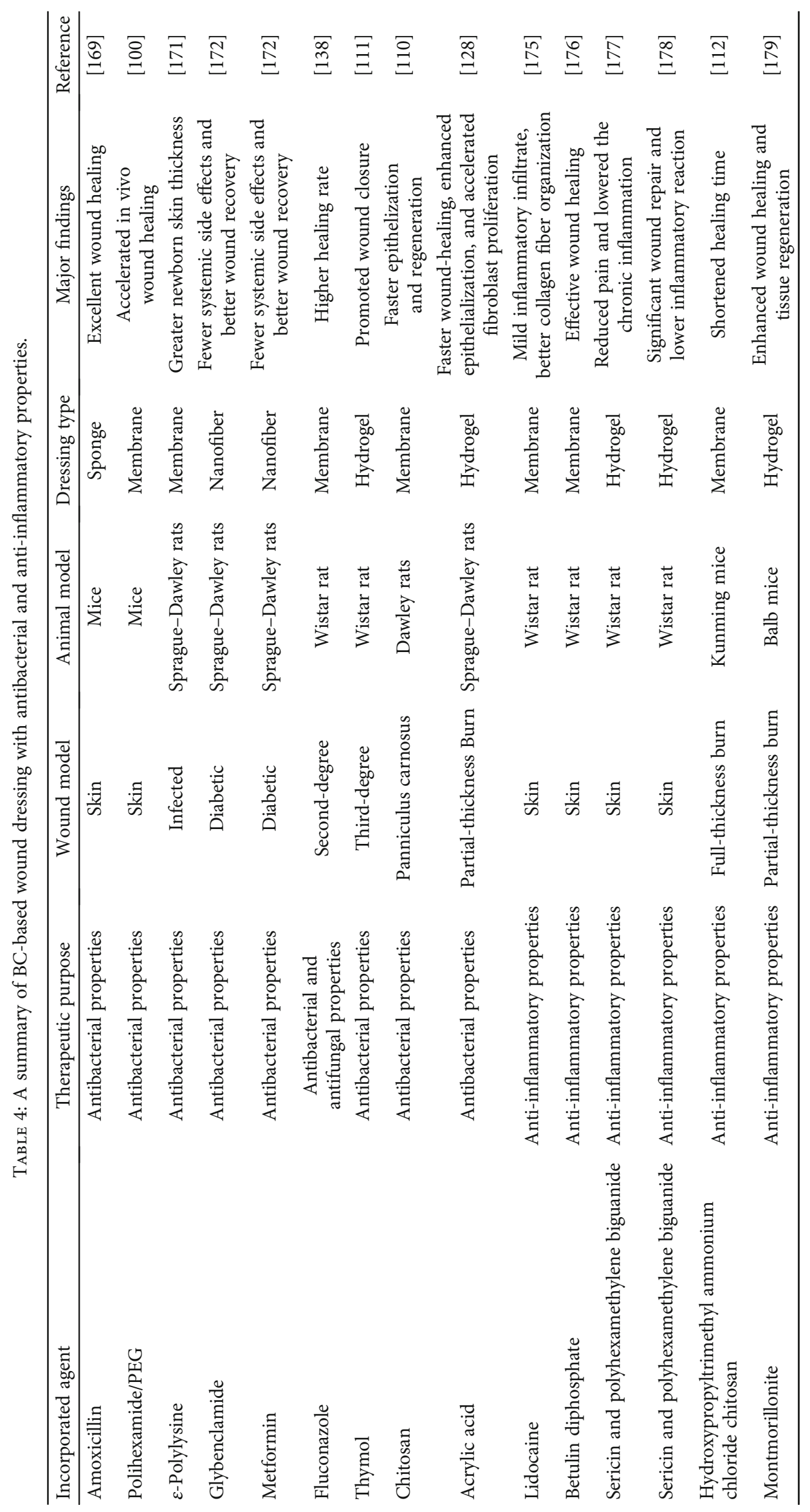




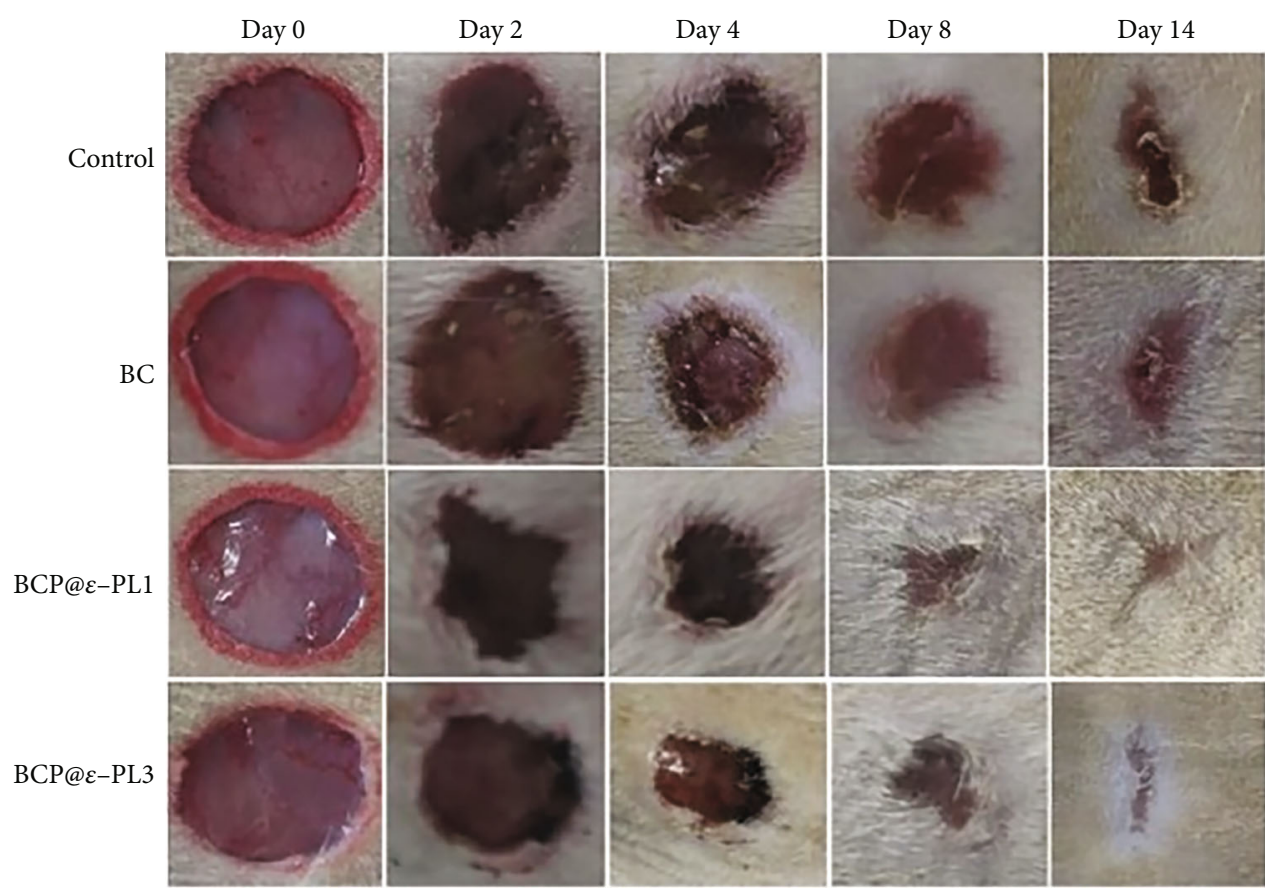

(a)

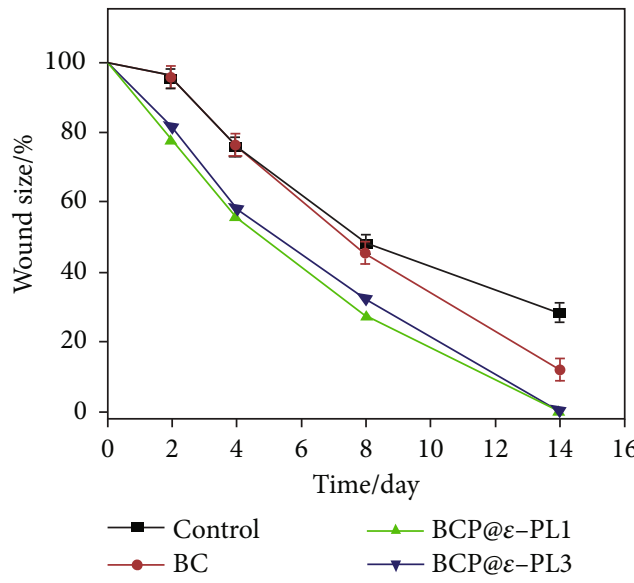

(b)

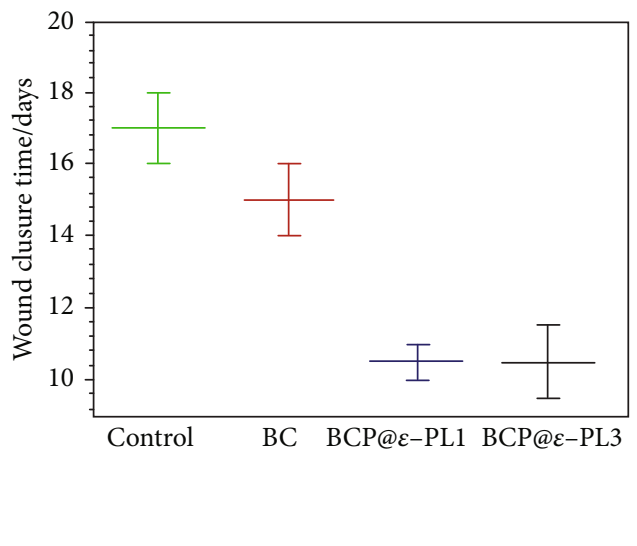

(c)

FIGURE 7: In vivo wound healing of $\varepsilon$-PL/BC membrane compared to that of BC. As can be seen, the functionalization of BC with $\varepsilon$-PL significantly accelerated the wound healing (a), reduced the wound size (b), and increased the wound closure (c), respectively, reprinted with permission [171].

epithelial cells compared to pure BC and BC-DOPA [127]. This was attributed to the release of $\mathrm{Ag}$ increasing the proliferation and migration of keratinocytes and GO, accelerating the cell proliferation by inhibiting bacterial growth (Figure 3).

Also, coating of BC with DOPA together with in situ reductions of Ag nanoparticles showed effective in vivo wound healing in Wistar rats [108]. This was attributed to the elimination of the pathogen, and reepithelization, and the modulation of inflammatory response. The dopamine (DOPA)-modified BC-GO-Ag supported the proliferation of NIH3-T3 fibroblast cells and showed antibacterial properties by the generation of large free oxidizing radicals than pure BC [167]. The modification of BC with 4,6-diamino- 2-pyrimidinethiol- (DAPT-) modified gold showed that $\mathrm{BC} / \mathrm{Au}-\mathrm{DAPT}$ is more efficient in preserving biocompatibility for human fibroblast cells and human umbilical vascular endothelial (HUVEC) cells in vivo on Wistar rat skin infected wounds [168]. This was due to the proliferation of fibroblasts in the wound and bacterial elimination decreasing the wound area (Figure 4).

10.2. Antibacterial Drugs. The loading of BC-based wound dressing with different antibacterial drugs was also used to enhance the efficiency of the BC-based wound dressing. The grafting of amoxicillin onto the regenerated bacterial cellulose (RBC) showed excellent wound healing performance in vivo in female mice compared to BC [169]. This 


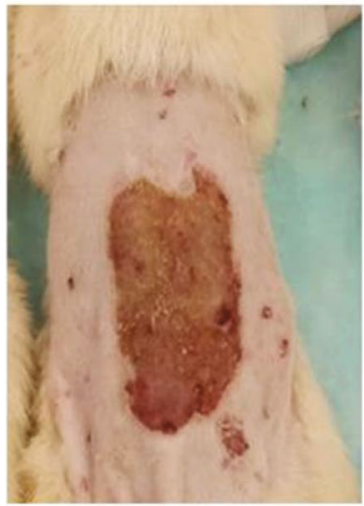

BC-ZnO NPs-BDP

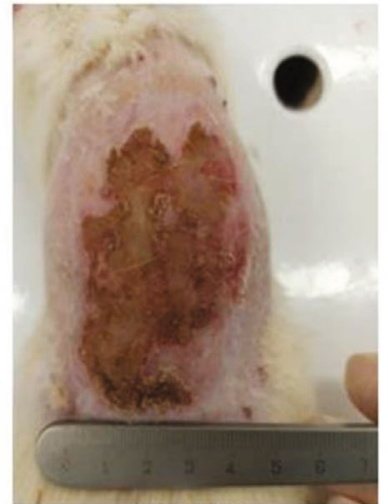

BC-BDP

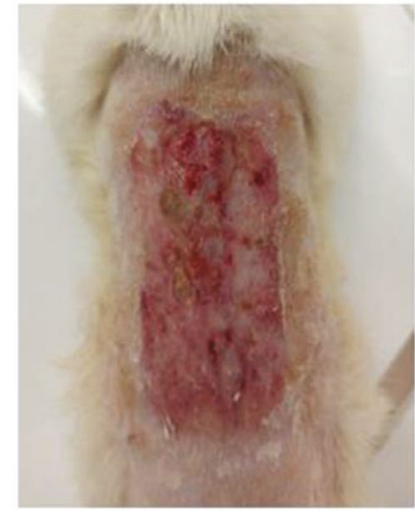

BC-ZnO NPs

Figure 8: The healing process of $\mathrm{BC}-\mathrm{ZnO}-\mathrm{BDP}, \mathrm{BC}-\mathrm{ZnO}$, and $\mathrm{BC}-\mathrm{BDP}$ after 21 days. As can be seen, the reduction of wound area was faster for $\mathrm{BC}-\mathrm{ZnO}-\mathrm{BDP}$ compared to BCP-ZnO [176].

was attributed to the antibacterial properties and good swelling properties of RBC wound dressing (Figure 5). The loading of bacterial nanocellulose sheet (BCN) with povidone-iodine (PI) and polihexamide (PHMB) showed both antiseptic properties and high biocompatibility in human keratinocytes [170]. Also, the loading of BC with PHMB and polyethylene glycol (PEG) showed an accelerated wound healing ability for PHMB/PEG/BC in vivo in mice than Biofill ${ }^{\circledR}$ and Biatain ${ }^{\circledR}$ commercial wound dressings (Figure 6) [100].

The fluconazole/never-dried bacterial cellulose (NBC) membrane also showed highly regenerative potential to treat burn wounds in vivo in Wistar rat wounds [138]. Also, $\varepsilon$ polylysine $(\varepsilon-\mathrm{PL}) / \mathrm{BC}$ membrane with mussel-inspired DOPA revealed greater newborn skin thickness in infected wounds in vivo in Sprague-Dawley rats compared to that of pure $\mathrm{BC}$ [171]. The $\mathrm{BC} /$ gelatin nanofibers were combined with glybenclamide $(\mathrm{Gb})$ and metformin (Met) drugs, and the results showed better recovery in vivo in SpragueDawley rat for Gb loaded BC/gelatin compared to Metloaded one. However, both of them revealed fewer systemic side effects upon treatment of diabetic wounds [172].

10.3. Antibacterial Polymers. Some specific polymers with antibacterial properties have also been exploited to improve the efficiency of the BC-based wound dressing (Table 4). The thymol/BC showed significantly increased wound healing performance in Wistar rats in vivo compared to pure BC scaffold [111]. This was ascribed to its antibacterial properties, which lead to a reduction in inflammation and better wound closure. Also, $\varepsilon$-polylysine $(\varepsilon-\mathrm{PL}) / \mathrm{BC}$ membrane showed greater wound healing and newborn skin thickness in infected wounds in vivo in Sprague-Dawley rats compared to that of pure BC (Figure 7) [171]. Furthermore, the loading of bacterial nanocellulose sheet $(\mathrm{BCN})$ with polihexamide (PHMB) was found to have antiseptic properties and show high biocompatibility in human keratinocytes [170]. Also, acetylated BC (AcBC) showed higher scratch closure with HaCaT cells compared to BC [173]. Further, the loading of chitosan on BC showed greater wound treatment in vivo in the Dawley rat model compared to transparent film dressing as well as Tegaderm commercial hydrocolloid dressing [110]. This was ascribed to the antibacterial properties and the better water adsorption capability leading to better reepithelization. Mohamad et al. have incorporated acrylic acid (AA) into BC and showed abundant neutrophils in the subcutaneous tissue, which removed the pathogens from the clot during injury. This enhanced the wound healing efficiency of BC/AA film than $\mathrm{BC}$ alone [128].

10.4. Anti-Inflammatory Agents. The wound healing process is dynamic and complex including several stages. The final product of thrombin is cyclooxygenase (COX-2), and its level is increased after skin damage. This improves the migration and proliferation of cells [174]. Brassolatti et al. have lidocaine on $\mathrm{BC}$ film and enhanced the immune expression of COX-2. Additionally, the skin appendages in the wound site showed a mild inflammatory infiltration, which promoted wound burn healing [175].

The immobilization of betulin diphosphate (BDP) as an anti-inflammatory agent on the $\mathrm{BC} / \mathrm{ZnO}$ revealed an effective wound healing in vivo in Wistar rats than $\mathrm{BC}$ which was attributed to the synergistic effects of reduced oxidative stress and regulated oxygenation (Figure 8) [176]. Also, the loading of $\mathrm{BC}$ with sericin and polyhexamethylene biguanide (PHMB) revealed that $\mathrm{BC} /$ sericin/PHMB reduced pain and lowered the chronic inflammation in vivo in Wistar rats compared to commercial Bactigras [177]. However, no significant difference was observed in wound healing time between BC dressing and split-thickness skin graft (STSG). Likewise, $\mathrm{BC} /$ sericin/PHMB showed a lower inflammatory response in vivo in Wistar rats compared to that of Bactigras commercial dressing with significant wound repair. Additionally, the dressing showed no irritating effects on healthy volunteers [178]. The hydroxypropyltrimethyl ammonium chloride chitosan (HACC) and collagen-I (CoL-I) were incorporated into $\mathrm{BC}$, and this enhanced the antibacterial properties of $\mathrm{BC}$ and promoted the in vivo wound healing in Kunming mice by shortening the healing time [112].

The combination of montmorillonite (MMT) with copper $(\mathrm{Cu})$ enhanced wound healing and tissue regeneration 

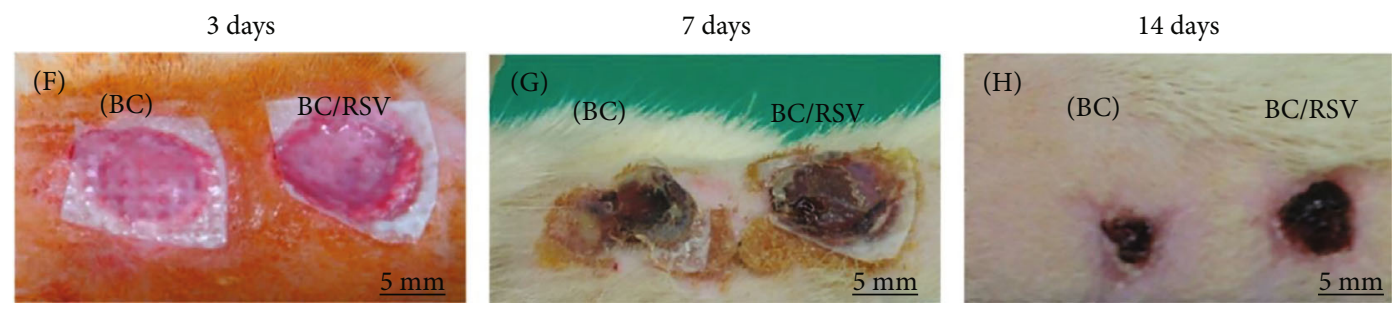

FIGURE 9: Effect of BC/RSV and BC scaffolds on dermal wound healing on rat skin defect after 3, 7, and 14 days. As can be observed, the RSV/BC scaffold did not show significant reduction in wound area but showed wound healing capability reproduced with permission [186].
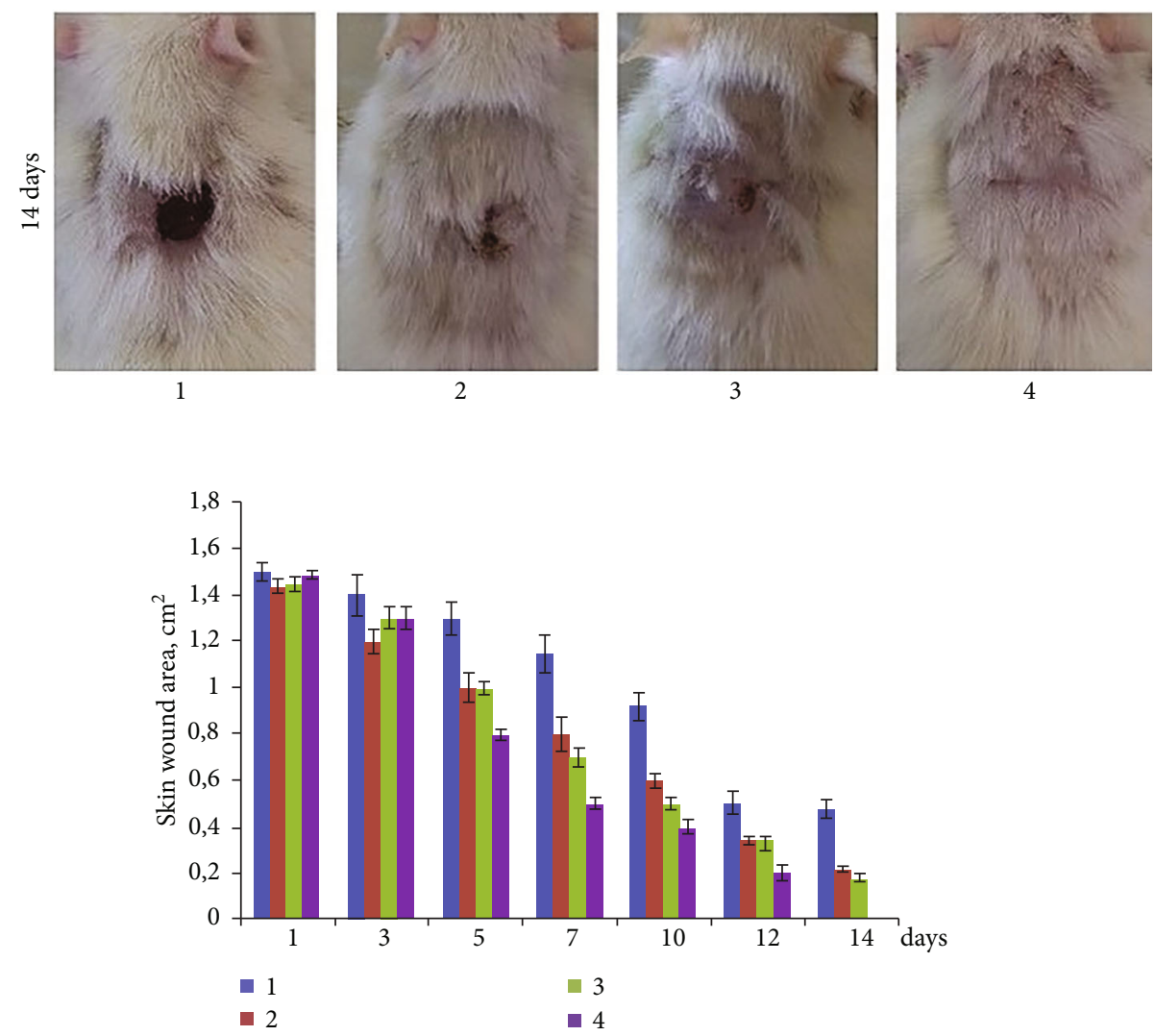

Figure 10: Macroscopic observation skin wound treated with different wound dressing materials: (1) VoskoPran, (2) P(3HB/4HB)/BC, (3) $\mathrm{P}(3 \mathrm{HB} / 4 \mathrm{HB}) / \mathrm{BC} /$ actovegin and (4) $\mathrm{P}(3 \mathrm{HB} / 4 \mathrm{HB}) /$ fibroblast, and skin wound area $\left(\mathrm{cm}^{2}\right)$, reproduced with permission [102].

in the $\mathrm{Balb} / \mathrm{c}$ mice after incorporation into $\mathrm{BC}$ [179]. The incorporation of MXene $\left(\mathrm{Ti}_{3} \mathrm{C}_{2} \mathrm{~T}_{\mathrm{x}}\right)$ into $\mathrm{BC}$ reduced the wound area and increased vascularization as well as reepithelization in vivo under electric field (EF) in full-thickness skin defect in Sprague-Dawley rat. The in vivo performance of the MXene/BC was found to be more effective than Tegaderm ${ }^{\circledR}$ commercial wound dressing film [121].

10.5. Natural Therapeutics. Natural products such as plants have shown a great therapeutic potential to be used in new dressing materials [180]. The combination of BC membrane with the propolis extract was found to show significantly higher healing capacity in vivo in diabetic mice models due to anti-inflammatory functions and supporting in vivo epithelization [181]. The loading of curcumin on BC significantly improved healing patterns than $\mathrm{BC}$ in vivo in the
Balb mice wound burn model [182]. Also, the loading of ionically modified $\mathrm{BC}(\mathrm{iBC}) /$ gelatin film with curcumin showed higher in vitro wound healing over NIH3T3 fibroblast cells than unloaded ones [183]. This was due to the better reepithelization, antibacterial properties, and reduced inflammatory reactions resulting from the presence of curcumin. The loading of polyelectrolyte film based on anionic modification of $\mathrm{BC}$ with curcumin was shown to accelerate the cell migration and proliferation and improve in vitro wound healing (scratch) [184]. Further, curcumin/hydroxypropyl- $\beta$-cyclodextrin complex was loaded on the BC-based hydrogel and the results showed cytocompatibility and antibacterial properties; however, no in vivo data was reported [185].

Also, microcolloidal Zanthoxylum acanthopodium (MZA) was loaded on the BC fibers, and this showed a 
TABLE 5: The wound healing rate of BC-based wound dressing.

\begin{tabular}{|c|c|c|c|c|}
\hline Wound dressing & BC wound healing rate (\%) & Modified BC wound healing rate (\%) & Control & Reference \\
\hline $\mathrm{BC} /$ thymol & 74.5 & 90 & 60 & [111] \\
\hline $\mathrm{BC} / \mathrm{PDA} / \mathrm{PAM}$ & $\mathrm{N} / \mathrm{A}$ & 100 & 85.7 & [196] \\
\hline BC/chitosan & 96 & 98 & 91 & {$[110]$} \\
\hline RBC/amoxicillin & 80 & 100 & 65 & [169] \\
\hline $\mathrm{BC} / \mathrm{DAPT}-\mathrm{Au}$ & 65 & 88 & 65 & {$[168]$} \\
\hline $\mathrm{BC} / \mathrm{TiO}_{2}$ & 49.14 & 71 & 73.71 & {$[163]$} \\
\hline $\mathrm{BC} / \mathrm{Cu}-\mathrm{MMT}$ & 38.75 & 75.08 & 76.01 & {$[179]$} \\
\hline $\mathrm{BC} / \mathrm{PHMB} /$ silk sericin & N/A & 100 & 92 & {$[178]$} \\
\hline BC/PHMB-PBC & 57.1 & 96.9 & 57.1 & {$[100]$} \\
\hline BC/PHMB-PBC & 57.1 & 96.9 & 57.1 & {$[100]$} \\
\hline $\mathrm{rBC} / \mathrm{MXene} / \mathrm{EF}$ & 76 & 93.8 & 87 & {$[121]$} \\
\hline $\mathrm{BC} / \mathrm{P}(3 \mathrm{HB} / 4 \mathrm{HB}) /$ actovegin & $\mathrm{N} / \mathrm{A}$ & 92.7 & 69.4 & {$[102]$} \\
\hline $\mathrm{BC} / \mathrm{P}(3 \mathrm{HB} / 4 \mathrm{HB}) /$ fibroblast & $\mathrm{N} / \mathrm{A}$ & 91 & 69.4 & {$[102]$} \\
\hline $\mathrm{BC} / \mathrm{ZnO}$ & 50.51 & 65.3 & 77.1 & [33] \\
\hline $\mathrm{BC} / \mathrm{PDA}$ & 74.58 & 94.35 & 65.35 & {$[108]$} \\
\hline $\mathrm{BC} /$ gel/Met & $\mathrm{N} / \mathrm{A}$ & 53.4 & 45 & {$[172]$} \\
\hline $\mathrm{BC} / \mathrm{gel} / \mathrm{Gb}$ & $\mathrm{N} / \mathrm{A}$ & 62.69 & 45 & {$[172]$} \\
\hline BD/Gly-DMAPA/si-MMP-9 & 59.88 & 74.07 & 45.28 & [192] \\
\hline $\mathrm{CNF} / \mathrm{G} / \mathrm{Ag}$ & 40 & 80 & 40 & {$[107]$} \\
\hline $\mathrm{BC} / \mathrm{SSD}$ & $\mathrm{N} / \mathrm{A}$ & 92.35 & 78.83 & {$[165]$} \\
\hline $\mathrm{BC} / \mathrm{Ag} \mathrm{NP}$ & 60.77 & 85.92 & 43.39 & {$[166]$} \\
\hline $\mathrm{BC} /$ curcumin & 41.60 & 64.25 & 30 & [182] \\
\hline $\mathrm{BC} / \mathrm{MZA}$ & 64.40 & 97.70 & 64.40 & {$[124]$} \\
\hline $\mathrm{BC} /$ Zingiber officinale & 80 & 68 & 65 & [187] \\
\hline
\end{tabular}

Controls: honey [187], untreated burn wound [124], silver sulfadiazine [182], untreated (gauze) [166], gauze [165], CNF[107], diabetic rat [192], untreated wound burn [172], untreated wound burn [108], silver sulfadiazine wounds [33], VoskoPran commercial dressing [102], commercial Tegaderm film dressing [121], pure BC membrane [100], commercial Bactigras wound dressing [178], silver sulfadiazine cream [179], silver sulfadiazine [163], pure BC [168]; untreated wound burn [169], pure BC [110], untreated wound burn [196], and untreated [111].

higher healing rate in vivo in brown rats (Rattus norvegicus) than $\mathrm{BC}$ due to the better vascularization and antibacterial properties as well as reduced inflammatory reactions [124]. Additionally, resveratrol (RSV) was conjugated with BC sheet, and the results showed better reepithelization in vivo in Sprague-Dawley rat with defect epidermis (Figure 9) [186]. However, it did not significantly reduce the wound area.

Further, BC film was combined with Zingiber officinale root aqueous extract, and this combination showed better wound healing in vivo in Wistar rats; however, the speed of wound healing was found to be slower than the counterpart alone [187]. Additionally, the combination of the extract of Jacaranda caroba (JC) and Calendula officinalis (CO) with BC hydrogel showed a faster and better reepithelization which were found in vivo in Rattus norvegicus rat compared to $\mathrm{BC}$ [188]. This was likely attributed to the lower inflammatory response. Further, the incorporation of Cinnamomum zeylanicum and chitosan into $\mathrm{BC}$ significantly promoted in vivo wound healing process in the skin excision of Wistar rats [189]. In addition, it showed more biocompatibility with L929 fibroblast cells than that of $\mathrm{BC}$ which could be due to better antibacterial and antifungal properties. Mirmohammadsadegh et al. have impregnated Pistacia atlantica fruit oil into the $\mathrm{BC}$ membrane and found faster wound closure in the burn wound model and better anti-inflammatory response than that of silver sulfadiazine and BC alone [190]. Actovegin was also loaded on $\mathrm{P}(3 \mathrm{HB} / 4 \mathrm{HB}) / \mathrm{BC}$ dressing which led to an acceleration of skin regeneration in vivo in female Wistar rats than that of VoskoPran commercial wound dressing [102] (Figure 10).

The incorporation of vaccaria segetalis extract (vaccarin) and the $\mathrm{BC}$ membrane showed a faster wound healing in the rat skin model in vivo than $\mathrm{BC}$ membrane alone due to the formation of dense newborn subcutaneous tissue and squamous epithelium [191]. Further, the encapsulation of matrix metalloproteinase 9 si-RNA (si-MMP-9) into the BC-hyperbranched cationic polysaccharide (BC-HCP) led to a significant wound healing rate in vivo in rat diabetic wounds [192]. This was ascribed to sustained release of MMP and downregulation of MMP-9 in diabetic wounds. In addition, the functionalization of $\mathrm{BC}$ with phenylalanine did not significantly affect scratch closure while functionalization with tryptophan negatively affects the in vitro scratch closure [173]. 


\section{Marketed BC-Based Wound Dressings}

The wound healing rate of some functionalized BC-based wound dressing is summarized in Table 5 . As can be observed, the modified BC-based wound dressing showed a higher percentage of wound healing compared to a pure BC-based wound dressing, commercial film dressing $[102,121,178]$, gauze $[165,166]$, and silver sulfadiazine $[33,163,179]$ and pure BC $[100,110,168]$. Although functionalized $\mathrm{BC}$ has shown potential encouraging characteristics to be used as wound dressing particularly for burn wounds, however, there are some BC-based wound dressings in the market such as bacterial nanocellulose [178], Nanoskin ${ }^{\circledR}$ [17], and CelMat ${ }^{\circledR}$ [17]. It is not widely commercially exploited. Despite the studies reviewed showing that the functionalization and modification of pure $\mathrm{BC}$ can enhance their in vitro and in vivo healing rates as wound dressing, there are not many BC-based commercial products for wound healing. For instance, PHMB-functionalized BC known as Suprasorb $\mathrm{X}^{\circledR}$ has been commercialized and marketed as wound dressing [193]. Another commercialized wound dressing is Biofill ${ }^{\circledR}$ which was used as temporary skin. It reduced infection, enhanced the healing rate, and relieved pain [194]. Other commercialized temporary skin is Membracel ${ }^{\circledR}$ for burns and ulcers which showed fast skin regeneration. In addition, commercialized $\mathrm{xCell}^{\circledR}$ was used as a dressing for venous ulcer wounds that relieved pain and accelerated granulation. Further, Nanoderm and Nanoderm Ag have been shown to prevent infections because of their antibacterial properties. Also, Nanoskin ${ }^{\circledR}$ was applied in chronic wounds which inhibited the entrance of microorganisms [73, 194]. Finally, the commercialized BC wound dressing CelMat ${ }^{\circledR}$ has been demonstrated to remove debris after cleaning [195].

\section{Conclusion and Future Perspective}

The wound healing and repair bring an immense burden economically and socially to the patient. Although conventional gauzes and bandages are known as common treatments for wound closure, however, they are susceptible to bacterial infection and cannot accelerate the wound healing process. To address these issues, recently many efforts have been adopted to develop novel and efficient wound dressing. Although BC-based hydrogel possesses attractive characteristics such as biocompatibility, high moisture, and waterretention capacity, however, the main drawback of pure BC-based hydrogel is the lack of antibacterial properties. We have reviewed and discussed common strategies to enhance the in vitro and in vivo efficiency of a BC-based wound dressing including their biofunctionalization and loading of natural therapeutics and antibacterial agents.

The mechanical behavior of BC-based wound dressing should be taken into consideration which represents opportunities to design BC-based hydrogel. Nonetheless, with respect to clinical applications of BC-based hydrogels, controlling the expenses and simplified manufacturing are research-directing issues in the laboratory. The loading of stem cells has been suggested as a potential therapeutic choice. However, it requires large-scale clinical trials. Nowadays, the state-of-the-art 3D and 4D printing biomaterials which mimic the extracellular matrix can offer a promising solution to wound treatment in the upcoming future. It is conceived that understanding the wound healing mechanism and microbiology of current wound dressing could assist the medical society to produce highly efficient wound dressing for individual patients.

\section{Data Availability}

The data used to support the findings of this study are included within the article.

\section{Conflicts of Interest}

The authors declare no conflict of interest.

\section{Acknowledgments}

We gratefully acknowledge the Kermanshah University of Medical Sciences for the support of this work (Grant No. 4000638).

\section{References}

[1] R. Rezaei, M. Safaei, H. R. Mozaffari et al., "The role of nanomaterials in the treatment of diseases and their effects on the immune system," Open Access Macedonian Journal of Medical Sciences, vol. 7, no. 11, pp. 1884-1890, 2019.

[2] H. R. Mozaffari, E. Zavattaro, A. Abdolahnejad et al., "Serum and salivary IgA, IgG, and IgM levels in oral lichen planus: a systematic review and meta-analysis of case-control studies," Medicina, vol. 54, no. 6, p. 99, 2018.

[3] M. Safaei, M. Taran, L. Jamshidy et al., "Optimum synthesis of polyhydroxybutyrate- $\mathrm{Co}_{3} \mathrm{O}_{4}$ bionanocomposite with the highest antibacterial activity against multidrug resistant bacteria," International Journal of Biological Macromolecules, vol. 158, pp. 477-485, 2020.

[4] H. Moradpoor, M. Safaei, F. Rezaei et al., "Optimisation of cobalt oxide nanoparticles synthesis as bactericidal agents, Open Access Macedonian," Journal of Medical Sciences, vol. 15, pp. 2757-2762, 2019.

[5] A. J. Singer and R. A. Clark, "Cutaneous wound healing," New England journal of medicine, vol. 341, no. 10, pp. 738746, 1999.

[6] M. Mühlstädt, C. Thomé, and C. Kunte, "Rapid wound healing of scalp wounds devoid of periosteum with milling of the outer table and split-thickness skin grafting," British Journal of Dermatology, vol. 167, no. 2, pp. 343-347, 2012.

[7] F. Siedenbiedel and J. C. Tiller, "Antimicrobial polymers in solution and on surfaces: overview and functional principles," Polymers, vol. 4, no. 1, pp. 46-71, 2012.

[8] A. F. Cardona and S. E. Wilson, "Skin and soft-tissue infections: a critical review and the role of telavancin in their treatment," Clinical Infectious Diseases, vol. 61, suppl 2, pp. S69-S78, 2015.

[9] H. P. Felgueiras and M. T. P. Amorim, "Functionalization of electrospun polymeric wound dressings with antimicrobial peptides," Colloids and Surfaces B: Biointerfaces, vol. 156, pp. 133-148, 2017. 
[10] J. S. Boateng, K. H. Matthews, H. N. E. Stevens, and G. M. Eccleston, "Wound healing dressings and drug delivery systems: a review," Journal of Pharmaceutical Sciences, vol. 97, no. 8, pp. 2892-2923, 2008.

[11] M. E. Okur, I. D. Karantas, Z. Şenyiğit, N. Üstündağ Okur, and P. I. Siafaka, "Recent trends on wound management: new therapeutic choices based on polymeric carriers," Asian Journal of Pharmaceutical Sciences, vol. 15, no. 6, pp. 661684, 2020.

[12] R. L. Reis, N. M. Neves, J. F. Mano, M. E. Gomes, A. P. Marques, and H. S. Azevedo, Natural-based polymers for biomedical applications, Elsevier, 2008.

[13] A. J. Brown, "XLIII.-On an acetic ferment which forms cellulose," Journal of the Chemical Society, Transactions, vol. 49, pp. 432-439, 1886.

[14] Y. Li, M. Lin, and J. W. Davenport, "Ab initio studies of cellulose I: crystal structure, intermolecular forces, and interactions with water," The Journal of Physical Chemistry C, vol. 115, no. 23, pp. 11533-11539, 2011.

[15] T. Carvalho, G. Guedes, F. L. Sousa, C. S. Freire, and H. A. Santos, "Latest advances on bacterial cellulose-based materials for wound healing, delivery systems, and tissue engineering," Biotechnology journal, vol. 14, no. 12, article 1900059, 2019.

[16] I. Sulaeva, U. Henniges, T. Rosenau, and A. Potthast, "Bacterial cellulose as a material for wound treatment: Properties and modifications. A review," Biotechnology advances, vol. 33, no. 8, pp. 1547-1571, 2015.

[17] R. Portela, C. R. Leal, P. L. Almeida, and R. G. Sobral, "Bacterial cellulose: a versatile biopolymer for wound dressing applications," Microbial Biotechnology, vol. 12, no. 4, pp. 586-610, 2019.

[18] A. D. Metcalfe and M. W. Ferguson, "Tissue engineering of replacement skin: the crossroads of biomaterials, wound healing, embryonic development, stem cells and regeneration," Journal of the Royal Society Interface, vol. 4, no. 14, pp. 413-437, 2007.

[19] A. A. Chaudhari, K. Vig, D. R. Baganizi et al., "Future prospects for scaffolding methods and biomaterials in skin tissue engineering: a review," International Journal of Molecular Sciences, vol. 17, no. 12, p. 1974, 2016.

[20] K. Vig, A. Chaudhari, S. Tripathi et al., "Advances in skin regeneration using tissue engineering," International Journal of Molecular Sciences, vol. 18, no. 4, p. 789, 2017.

[21] S. Dhivya, V. V. Padma, and E. Santhini, "Wound dressings a review," Biomedicine (Taipei), vol. 5, no. 4, pp. 1-5, 2015.

[22] K. Järbrink, G. Ni, H. Sönnergren et al., "Prevalence and incidence of chronic wounds and related complications: a protocol for a systematic review," Systematic Reviews, vol. 5, p. 152, 2016.

[23] S. A. Eming, P. Martin, and M. Tomic-Canic, "Wound repair and regeneration: mechanisms, signaling, and translation," Science translational medicine, vol. 6, no. 265, p. 265sr6, 2014.

[24] P. I. Morgado, A. Aguiar-Ricardo, and I. J. Correia, “Asymmetric membranes as ideal wound dressings: An overview on production methods, structure, properties and performance relationship," Journal of Membrane Science, vol. 490, pp. 139-151, 2015.

[25] T. Velnar, T. Bailey, and V. Smrkolj, "The wound healing process: an overview of the cellular and molecular mecha- nisms," Journal of International Medical Research, vol. 37, pp. 1528-1542, 2009.

[26] F. M. Thiruvoth, D. P. Mohapatra, D. Kumar, S. R. K. Chittoria, and V. Nandhagopal, "Current concepts in the physiology of adult wound healing," Plastic and Aesthetic Research, vol. 2, pp. 250-256, 2015.

[27] L. I. F. Moura, A. M. A. Dias, E. Carvalho, and H. C. de Sousa, "Recent advances on the development of wound dressings for diabetic foot ulcer treatment-a review," Acta Biomaterialia, vol. 9, pp. 7093-7114, 2013.

[28] N. Mohamad, F. Buang, A. Mat Lazim, N. Ahmad, C. Martin, and M. C. I. Mohd Amin, "Characterization and biocompatibility evaluation of bacterial cellulose-based wound dressing hydrogel: effect of electron beam irradiation doses and concentration of acrylic acid," Journal of biomedical materials research. Part B, Applied biomaterials, vol. 105, no. 8, pp. 2553-2564, 2017.

[29] A. Gosain and L. A. DiPietro, "Aging and wound healing," World journal of surgery, vol. 28, pp. 321-326, 2004.

[30] L. A. Schneider, A. Korber, S. Grabbe, and J. Dissemond, "Influence of $\mathrm{pH}$ on wound-healing: a new perspective for wound-therapy?," Archives of dermatological research, vol. 298, pp. 413-420, 2007.

[31] S. L. Percival, S. McCarty, J. A. Hunt, and E. J. Woods, "The effects of $\mathrm{pH}$ on wound healing, biofilms, and antimicrobial efficacy," Wound repair and regeneration, vol. 22, pp. 174186, 2014.

[32] P. Pourali, N. Razavianzadeh, L. Khojasteh, and B. Yahyaei, "Assessment of the cutaneous wound healing efficiency of acidic, neutral and alkaline bacterial cellulose membrane in rat," Journal of Materials Science: Materials in Medicine, vol. 29, p. 90, 2018.

[33] A. Khalid, R. Khan, M. Ul-Islam, T. Khan, and F. Wahid, "Bacterial cellulose-zinc oxide nanocomposites as a novel dressing system for burn wounds," Carbohydrate Polymers, vol. 164, pp. 214-221, 2017.

[34] G. B. Pitzer and K. G. Patel, "Proper care of early wounds to optimize healing and prevent complications," Facial Plastic Surgery Clinics of North America, vol. 19, no. 3, pp. 491504, 2011.

[35] J. Lu, M. Yang, M. Zhan et al., "Antibiotics for treating infected burn wounds," The Cochrane Database of Systematic Reviews, vol. 2017, 2017.

[36] D. Church, S. Elsayed, O. Reid, B. Winston, and R. Lindsay, "Burn wound infections," Clinical microbiology reviews, vol. 19, pp. 403-434, 2006.

[37] R. Edwards and K. G. Harding, "Bacteria and wound healing," Current opinion in infectious diseases, vol. 17, pp. 9196, 2004.

[38] S. Laube, "Skin infections and ageing," Ageing research reviews, vol. 3, pp. 69-89, 2004.

[39] S. R. Shah, F. K. Kasper, and A. G. Mikos, "Perspectives on the prevention and treatment of infection for orthopedic tissue engineering applications," Chinese Science Bulletin, vol. 58, pp. 4342-4348, 2013.

[40] H. Calum, C. Moser, P. Ø. Jensen et al., “Thermal injury induces impaired function in polymorphonuclear neutrophil granulocytes and reduced control of burn wound infection," Clinical \& Experimental Immunology, vol. 156, no. 1, pp. 102-110, 2009. 
[41] V. Sukumaran and S. Senanayake, "Bacterial skin and soft tissue infections," Australian prescriber, vol. 39, p. 159, 2016.

[42] O. Sarheed, A. Ahmed, D. Shouqair, and J. Boateng, "Antimicrobial dressings for improving wound healing," Wound Healing-New Insights into Ancient Challenges, V. Alexandrescu, Ed., pp. 373-398, 2016.

[43] N. Woodford and D. M. Livermore, "Infections caused by Gram-positive bacteria: a review of the global challenge," Journal of Infection, vol. 59, pp. S4-S16, 2009.

[44] P. Chen, G. He, J. Qian, Y. Zhan, and R. Xiao, "Potential role of the skin microbiota in Inflammatory skin diseases," Journal of Cosmetic Dermatology, vol. 20, pp. 400-409, 2021.

[45] T. Nakatsuji, T. H. Chen, A. M. Butcher et al., "A commensal strain ofStaphylococcus epidermidisprotects against skin neoplasia," Advances, vol. 4, no. 2, article eaao4502, 2018.

[46] H. A. Jasim, "Study of type of bacteria that found in ear, mouth, nose of second stage nursing department student," Indian Journal of Forensic Medicine \& Toxicology, vol. 14, 2020.

[47] V. Gautam, N. Sethuraman, R. Kaur, S. Sachdev, N. Marwaha, and P. Ray, "Changing epidemiology of coagulase-negative staphylococci in normal flora of skin," Indian journal of medical microbiology, vol. 35, pp. 277-278, 2017.

[48] K. Szabó, L. Erdei, B. S. Bolla, G. Tax, T. Bíró, and L. Kemény, "Factors shaping the composition of the cutaneous microbiota," British Journal of Dermatology, vol. 176, pp. 344-351, 2017.

[49] J. A. Sanford and R. L. Gallo, "Functions of the skin microbiota in health and disease," in Seminars in immunology, pp. 370-377, Elsevier, 2013.

[50] E. Laborel-Préneron, P. Bianchi, F. Boralevi et al., "Effects of the Staphylococcus aureus and Staphylococcus epidermidis secretomes isolated from the skin microbiota of atopic children on CD4+ T cell activation," PLoS One, vol. 10, no. 10, article e0141067, 2015.

[51] C. Leonel, I. F. G. Sena, W. N. Silva et al., "Staphylococcus epidermidis role in the skin microenvironment," Journal of Cellular and Molecular Medicine, vol. 23, pp. 5949-5955, 2019.

[52] M. Otto, "Staphylococci in the human microbiome: the role of host and interbacterial interactions," Current opinion in microbiology, vol. 53, pp. 71-77, 2020.

[53] Y. J. Park and H. K. Lee, "The role of skin and orogenital microbiota in protective immunity and chronic immunemediated inflammatory disease," Frontiers in immunology, vol. 8, p. 1955, 2018.

[54] M. Coates, S. Blanchard, and A. S. MacLeod, "Innate antimicrobial immunity in the skin: a protective barrier against bacteria, viruses, and fungi," PLoS pathogens, vol. 14, article e1007353, 2018.

[55] T. Maheswary, A. A. Nurul, and M. B. Fauzi, "The insights of microbes' roles in wound healing: a comprehensive review," Pharmaceutics, vol. 13, p. 981, 2021.

[56] D. Simões, S. P. Miguel, M. P. Ribeiro, P. Coutinho, A. G. Mendonça, and I. J. Correia, "Recent advances on antimicrobial wound dressing: a review," European Journal of Pharmaceutics and Biopharmaceutics, vol. 127, pp. 130-141, 2018.

[57] F. S. Pott, M. J. Meier, J. G. D. Stocco, K. Crozeta, and J. D. Ribas, "The effectiveness of hydrocolloid dressings versus other dressings in the healing of pressure ulcers in adults and older adults: a systematic review and meta-analysis1," Revista latino-americana de enfermagem, vol. 22, pp. 511520, 2014.

[58] P. Zahedi, I. Rezaeian, S. O. Ranaei-Siadat, S. H. Jafari, and P. Supaphol, "A review on wound dressings with an emphasis on electrospun nanofibrous polymeric bandages," Polymers for Advanced Technologies, vol. 21, pp. 77-95, 2010.

[59] E. Caló and V. V. Khutoryanskiy, "Biomedical applications of hydrogels: a review of patents and commercial products," European Polymer Journal, vol. 65, pp. 252-267, 2015.

[60] L. Bacakova, J. Pajorova, M. Bacakova et al., "Versatile application of nanocellulose: from industry to skin tissue engineering and wound healing," Nanomaterials, vol. 9, no. 2, p. 164, 2019.

[61] H. G. de Oliveira Barud, R. R. da Silva, H. da Silva Barud et al., "A multipurpose natural and renewable polymer in medical applications: bacterial cellulose," Carbohydrate Polymers, vol. 153, pp. 406-420, 2016.

[62] L. D. Marestoni, H. D. Barud, R. J. Gomes et al., "Commercial and potential applications of bacterial cellulose in Brazil: ten years review," Polímeros, vol. 30, 2021.

[63] H. G. de Oliveira Barud, R. R. da Silva, M. A. Borges, G. R. Castro, S. J. Ribeiro, and H. da Silva Barud, "Bacterial nanocellulose in dentistry: perspectives and challenges," Molecules, vol. 26, p. 49, 2021.

[64] Z. Shi, M. W. Ullah, X. Liang, and G. Yang, "Recent developments in synthesis, properties, and biomedical applications of cellulose-based hydrogels," Nanocellulose: Synthesis, Structure, Properties and Applications, pp. 121-153, 2021.

[65] M. Safaei and M. Taran, "Preparation of bacterial cellulose fungicide nanocomposite incorporated with $\mathrm{MgO}$ nanoparticles," Journal of Polymers and the Environment, 2022.

[66] W. Liu, H. Du, T. Zheng, and C. Si, "Biomedical Applications of Bacterial Cellulose based Composite Hydrogels," Current Medicinal Chemistry, vol. 28, no. 40, pp. 1-11, 2021.

[67] L. J. Del Valle, A. Díaz, and J. Puiggalí, "Hydrogels for biomedical applications: cellulose, chitosan, and protein/peptide derivatives," Gels, vol. 3, p. 27, 2017.

[68] L. F. Farah, Process for the preparation of cellulose film, cellulose film produced thereby, artificial skin graft and its use, Google Patents, 1990.

[69] D. F. Ring, W. Nashed, and T. Dow, Liquid loaded pad for medical applications, Google Patents, 1986.

[70] C. Zhijiang and Y. Guang, "Bacterial cellulose/collagen composite: Characterization and first evaluation of cytocompatibility," Journal of Applied Polymer Science, vol. 120, pp. 2938-2944, 2011.

[71] L. Fu, Y. Zhang, C. Li et al., "Skin tissue repair materials from bacterial cellulose by a multilayer fermentation method," Journal of Materials Chemistry, vol. 22, pp. 12349-12357, 2012.

[72] W. Czaja, A. Krystynowicz, S. Bielecki, and R. M. Brown, "Microbial cellulose-the natural power to heal wounds," Biomaterials, vol. 27, pp. 145-151, 2006.

[73] W. K. Czaja, D. J. Young, M. Kawecki, and R. M. Brown, "The future prospects of microbial cellulose in biomedical applications," Biomacromolecules, vol. 8, pp. 1-12, 2007.

[74] N. Shah, M. Ul-Islam, W. A. Khattak, and J. K. Park, "Overview of bacterial cellulose composites: a multipurpose advanced material," Carbohydrate Polymers, vol. 98, pp. 1585-1598, 2013. 
[75] N. Mohamad, E. Y. X. Loh, M. B. Fauzi, M. H. Ng, and M. C. I. Mohd Amin, "In vivo evaluation of bacterial cellulose/ acrylic acid wound dressing hydrogel containing keratinocytes and fibroblasts for burn wounds," Drug Delivery and Translational Research, vol. 9, no. 2, pp. 444-452, 2019.

[76] A. Meftahi, R. Khajavi, A. Rashidi, M. Sattari, M. Yazdanshenas, and M. Torabi, "The effects of cotton gauze coating with microbial cellulose," Cellulose, vol. 17, pp. 199-204, 2010.

[77] Y. Li, S. Wang, R. Huang et al., "Evaluation of the effect of the structure of bacterial cellulose on full thickness skin wound repair on a microfluidic chip," Biomacromolecules, vol. 16, pp. 780-789, 2015.

[78] L. M. Cavalcanti, F. C. M. Pinto, G. M. Oliveira, S. V. C. Lima, J. L. A. Aguiar, and E. M. Lins, "Efficacy of bacterial cellulose membrane for the treatment of lower limbs chronic varicose ulcers: a randomized and controlled trial," Revista do Colegio Brasileiro de Cirurgioes, vol. 44, pp. 72-80, 2017.

[79] D. R. Solway, M. Consalter, and D. J. Levinson, "Microbial cellulose wound dressing in the treatment of skin tears in the frail elderly," Wounds : a compendium of clinical research and practice, vol. 22, no. 1, pp. 17-19, 2010.

[80] O. Portal, W. A. Clark, and D. J. Levinson, "Microbial cellulose wound dressing in the treatment of nonhealing lower extremity ulcers," Wounds : a compendium of clinical research and practice, vol. 21, pp. 1-3, 2009.

[81] L. G. Silva, A. V. Albuquerque, F. C. M. Pinto, R. S. FerrazCarvalho, J. L. A. Aguiar, and E. M. Lins, "Bacterial cellulose an effective material in the treatment of chronic venous ulcers of the lower limbs," Journal of Materials Science: Materials in Medicine, vol. 32, p. 79, 2021.

[82] A. Piatkowski, N. Drummer, A. Andriessen, D. Ulrich, and N. Pallua, "Randomized controlled single center study comparing a polyhexanide containing bio-cellulose dressing with silver sulfadiazine cream in partial-thickness dermal burns," Burns, vol. 37, pp. 800-804, 2011.

[83] M. Schmitz, T. Eberlein, and A. Andriessen, "Wound treatment costs comparing a bio-cellulose dressing with moist wound healing dressings and conventional dressings," Wound Medicine, vol. 6, pp. 11-14, 2014.

[84] K. Kowalska-Ludwicka, J. Cala, B. Grobelski et al., "Modified bacterial cellulose tubes for regeneration of damaged peripheral nerves," Archives of medical science: AMS, vol. 9, p. 527, 2013.

[85] A. Agarwal, J. McAnulty, M. Schurr, C. Murphy, and N. Abbott, "Polymeric materials for chronic wound and burn dressings," in Advanced Wound Repair Therapies, D. Farrar, Ed., pp. 186-208, Woodhead Publishing, 2011.

[86] L. G. Ovington, "Advances in wound dressings," Clinics in Dermatology, vol. 25, pp. 33-38, 2007.

[87] D. Klemm, F. Kramer, S. Moritz et al., "Nanocelluloses: a new family of nature-based materials," Angewandte Chemie International Edition, vol. 50, no. 24, pp. 54385466, 2011.

[88] I. Almeida, T. Pereira, N. Silva et al., "Bacterial cellulose membranes as drug delivery systems: An in vivo skin compatibility study," European Journal of Pharmaceutics and Biopharmaceutics, vol. 86, pp. 332-336, 2014.

[89] F. G. Torres, S. Commeaux, and O. P. Troncoso, "Biocompatibility of bacterial cellulose based biomaterials," Journal of functional biomaterials, vol. 3, pp. 864-878, 2012.
[90] S. T. Schrecker and P. A. Gostomski, "Determining the water holding capacity of microbial cellulose," Biotechnology Letters, vol. 27, pp. 1435-1438, 2005.

[91] M. Iguchi, S. Yamanaka, and A. Budhiono, "Bacterial cellulose-a masterpiece of nature's arts," Journal of Materials Science, vol. 35, pp. 261-270, 2000.

[92] N. T. Laçin, "Development of biodegradable antibacterial cellulose based hydrogel membranes for wound healing," International Journal of Biological Macromolecules, vol. 67, pp. 22-27, 2014.

[93] R. Song, M. Murphy, C. Li, K. Ting, C. Soo, and Z. Zheng, "Current development of biodegradable polymeric materials for biomedical applications," Drug design, development and therapy, vol. Volume 12, pp. 3117-3145, 2018.

[94] K. Ginjupalli, G. V. Shavi, R. K. Averineni, M. Bhat, N. Udupa, and P. N. Upadhya, "Poly ( $\alpha$-hydroxy acid) based polymers: a review on material and degradation aspects," Polymer Degradation and Stability, vol. 144, pp. 520-535, 2017.

[95] M. E. Gomes and R. Reis, "Biodegradable polymers and composites in biomedical applications: from catgut to tissue engineering. Part 1 Available systems and their properties," International materials reviews, vol. 49, pp. 261-273, 2004.

[96] S. Deshayes and A. M. Kasko, "Polymeric biomaterials with engineered degradation," Journal of Polymer Science Part A: Polymer Chemistry, vol. 51, pp. 3531-3566, 2013.

[97] B. D. Ulery, L. S. Nair, and C. T. Laurencin, "Biomedical applications of biodegradable polymers," Journal of polymer science Part B: polymer physics, vol. 49, pp. 832-864, 2011.

[98] Y. Hou, X. Wang, J. Yang, R. Zhu, Z. Zhang, and Y. Li, "Development and biocompatibility evaluation of biodegradable bacterial cellulose as a novel peripheral nerve scaffold," Journal of Biomedical Materials Research Part A, vol. 106, pp. 1288-1298, 2018.

[99] S. Torgbo and P. Sukyai, "Biodegradation and thermal stability of bacterial cellulose as biomaterial: the relevance in biomedical applications," Polymer Degradation and Stability, vol. 179, article 109232, 2020.

[100] Y. Wang, C. Wang, Y. Xie et al., "Highly transparent, highly flexible composite membrane with multiple antimicrobial effects used for promoting wound healing," Carbohydrate Polymers, vol. 222, article 114985, 2019.

[101] E. Y. X. Loh, N. Mohamad, M. B. Fauzi, M. H. Ng, S. F. Ng, and M. C. I. Mohd Amin, "Development of a bacterial cellulose-based hydrogel cell carrier containing keratinocytes and fibroblasts for full-thickness wound healing," Scientific Reports, vol. 8, p. 2875, 2018.

[102] T. Volova, A. Shumilova, E. Nikolaeva, A. Kirichenko, and E. Shishatskaya, "Biotechnological wound dressings based on bacterial cellulose and degradable copolymer P (3HB/ 4HB)," International journal of biological macromolecules, vol. 131, pp. 230-240, 2019.

[103] D. Farrar, Advanced wound repair therapies, Elsevier, 2011.

[104] J. R. Davidson, "Current concepts in wound management and wound healing products," Veterinary Clinics: Small Animal Practice, vol. 45, no. 3, pp. 537-564, 2015.

[105] W. Paul and C. P. Sharma, "Chitosan and alginate wound dressings: a short review," Trends in Biomaterials \& Artificial Organs, vol. 18, pp. 18-23, 2004.

[106] Y.-B. Wu, S.-H. Yu, F.-L. Mi et al., "Preparation and characterization on mechanical and antibacterial properties of 
chitsoan/cellulose blends," Carbohydrate Polymers, vol. 57, pp. 435-440, 2004.

[107] R. Liu, L. Dai, C. Si, and Z. Zeng, "Antibacterial and hemostatic hydrogel via nanocomposite from cellulose nanofibers," Carbohydrate Polymers, vol. 195, pp. 63-70, 2018.

[108] S. Jiji, S. Udhayakumar, K. Maharajan, C. Rose, C. Muralidharan, and K. Kadirvelu, "Bacterial cellulose matrix with in situ impregnation of silver nanoparticles via catecholic redox chemistry for third degree burn wound healing," Carbohydrate Polymers, vol. 245, article 116573, 2020.

[109] Z. Luo, J. Liu, H. Lin et al., "In situ fabrication of nano $\mathrm{ZnO} /$ BCM biocomposite based on MA modified bacterial cellulose membrane for antibacterial and wound healing," International journal of nanomedicine, vol. 15, pp. 1-15, 2020.

[110] W.-C. Lin, C.-C. Lien, H.-J. Yeh, C.-M. Yu, and S. H. Hsu, "Bacterial cellulose and bacterial cellulose-chitosan membranes for wound dressing applications," Carbohydrate Polymers, vol. 94, no. 1, pp. 603-611, 2013.

[111] S. Jiji, S. Udhayakumar, C. Rose, C. Muralidharan, and K. Kadirvelu, "Thymol enriched bacterial cellulose hydrogel as effective material for third degree burn wound repair," International Journal of Biological Macromolecules, vol. 122, pp. 452-460, 2019.

[112] C. Zhou, Z. Yang, X. Xun et al., "De novo strategy with engineering a multifunctional bacterial cellulose-based dressing for rapid healing of infected wounds," Bioactive Materials, 2021.

[113] W.-S. Chang and H.-H. Chen, "Physical properties of bacterial cellulose composites for wound dressings," Food Hydrocolloids, vol. 53, pp. 75-83, 2016.

[114] D. Ciecholewska-Juśko, A. Żywicka, A. Junka et al., "Superabsorbent crosslinked bacterial cellulose biomaterials for chronic wound dressings," Carbohydrate Polymers, vol. 253, article 117247, 2021.

[115] N. Kanjanamosit, C. Muangnapoh, and M. Phisalaphong, "Biosynthesis and characterization of bacteria cellulose-alginate film," Journal of Applied Polymer Science, vol. 115, pp. 1581-1588, 2010.

[116] K. Król-Morkisz and K. Pielichowska, "13 - Thermal decomposition of polymer nanocomposites with functionalized nanoparticles," in Polymer Composites with Functionalized Nanoparticles, K. Pielichowski and T. M. Majka, Eds., pp. 405-435, Elsevier, 2019.

[117] M. Nachiappan, D. Gurusinghe, and S. Bhandari, "Hypothermia in burns intensive care: use of the intravenous temperature management system Thermogard $\mathrm{XP}{ }^{\circledR}, "$ Critical Care, vol. 16, no. S2, p. A15, 2012.

[118] E. Shim, J. Su, J. Noro et al., "Conductive bacterial cellulose by in situ laccase polymerization of aniline," PloS one, vol. 14, article e0214546, 2019.

[119] N. F. Vasconcelos, F. K. Andrade, L. . A. P. Vieira et al., "Oxidized bacterial cellulose membrane as support for enzyme immobilization: properties and morphological features," Cellulose, vol. 27, no. 6, pp. 3055-3083, 2020.

[120] A. F. Costa, F. C. Almeida, G. M. Vinhas, and L. A. Sarubbo, "Production of bacterial cellulose by Gluconacetobacter hansenii using corn steep liquor as nutrient sources," Frontiers in microbiology, vol. 8, p. 2027, 2017.

[121] L. Mao, S. Hu, Y. Gao et al., "Biodegradable and electroactive regenerated nacterial cellulose/MXene (Ti3C2Tx) composite hydrogel as wound dressing for accelerating skin wound heal- ing under Electrical stimulation," Advanced Healthcare Materials, vol. 9, article 2000872, 2020.

[122] L. Wang, L. Mao, F. Qi et al., "Synergistic effect of highly aligned bacterial cellulose/gelatin membranes and electrical stimulation on directional cell migration for accelerated wound healing," Chemical Engineering Journal, vol. 424, article 130563, 2021.

[123] M. L. Cacicedo, G. Pacheco, G. A. Islan, V. A. Alvarez, H. S. Barud, and G. R. Castro, "Chitosan-bacterial cellulose patch of ciprofloxacin for wound dressing: preparation and characterization studies," International Journal of Biological Macromolecules, vol. 147, pp. 1136-1145, 2020.

[124] K. M. Pasaribu, S. Gea, S. Ilyas et al., "Fabrication and in-vivo study of micro-colloidal Zanthoxylum acanthopodiumloaded bacterial cellulose as a burn wound dressing," Polymers, vol. 12, p. 1436, 2020.

[125] Z. Keskin, A. Sendemir Urkmez, and E. E. Hames, "Novel keratin modified bacterial cellulose nanocomposite production and characterization for skin tissue engineering," Materials Science and Engineering: C, vol. 75, pp. 1144-1153, 2017.

[126] L. Lamboni, Y. Li, J. Liu, and G. Yang, "Silk sericinfunctionalized bacterial cellulose as a potential woundhealing biomaterial," Biomacromolecules, vol. 17, no. 9, pp. 3076-3084, 2016.

[127] M. Khamrai, S. L. Banerjee, S. Paul, A. K. Ghosh, P. Sarkar, and P. P. Kundu, "A mussel mimetic, bioadhesive, antimicrobial patch based on dopamine-modified bacterial cellulose/ rGO/Ag NPs: a green approach toward wound-healing applications," ACS Sustainable Chemistry \& Engineering, vol. 7, pp. 12083-12097, 2019.

[128] N. Mohamad, M. C. I. Mohd Amin, M. Pandey, N. Ahmad, and N. F. Rajab, "Bacterial cellulose/acrylic acid hydrogel synthesized via electron beam irradiation: accelerated burn wound healing in an animal model," Carbohydrate Polymers, vol. 114, pp. 312-320, 2014.

[129] P. R. Moraes, S. Saska, H. Barud et al., "Bacterial cellulose/collagen hydrogel for wound healing," Materials Research, vol. 19, pp. 106-116, 2016.

[130] S. Tang, K. Chi, H. Xu, Q. Yong, J. Yang, and J. M. Catchmark, "A covalently cross-linked hyaluronic acid/ bacterial cellulose composite hydrogel for potential biological applications," Carbohydrate Polymers, vol. 252, article 117123, 2021.

[131] S. Khan, M. Ul-Islam, M. Ikram et al., "Preparation and structural characterization of surface modified microporous bacterial cellulose scaffolds: a potential material for skin regeneration applications in vitro and in vivo," International Journal of Biological Macromolecules, vol. 117, pp. 12001210, 2018.

[132] J. Kingkaew, S. Kirdponpattara, N. Sanchavanakit, P. Pavasant, and M. Phisalaphong, "Effect of molecular weight of chitosan on antimicrobial properties and tissue compatibility of chitosan-impregnated bacterial cellulose films," Biotechnology and Bioprocess Engineering, vol. 19, pp. 534-544, 2014.

[133] Y. Li, H. Jiang, W. Zheng et al., "Bacterial cellulose-hyaluronan nanocomposite biomaterials as wound dressings for severe skin injury repair," Journal of Materials Chemistry B, vol. 3, no. 17, pp. 3498-3507, 2015.

[134] C. D. Radu, L. Verestiuc, E. Ulea et al., "Evaluation of keratin/ bacterial cellulose based scaffolds as potential burned wound dressing," Applied Sciences, vol. 11, p. 1995, 2021. 
[135] S.-P. Lin, H.-N. Kung, Y.-S. Tsai, T.-N. Tseng, K.-D. Hsu, and K.-C. Cheng, "Novel dextran modified bacterial cellulose hydrogel accelerating cutaneous wound healing," Cellulose, vol. 24, pp. 4927-4937, 2017.

[136] H. Qiao, T. Guo, Y. Zheng et al., “A novel microporous oxidized bacterial cellulose/arginine composite and its effect on behavior of fibroblast/endothelial cell," Carbohydrate Polymers, vol. 184, pp. 323-332, 2018.

[137] F. Farideh, M. Mohsen, and T. Azade, "Arginine Functionalized Bacterial Cellulose Nanofibers Containing Gel as an Effective Wound Dressing: In vitro and In vivo Evaluation," Current Drug Delivery, vol. 15, no. 6, pp. 840-849, 2018.

[138] C. M. Souza, L. A. Mesquita, D. Souza et al., "Regeneration of skin tissue promoted by mesenchymal stem cells seeded in nanostructured membrane," Transplantation proceedings, vol. 46, pp. 1882-1886, 2014.

[139] M. de Alencar Silva, Y. K. de Carvalho Leite, C. E. de Carvalho et al., "Behavior and biocompatibility of rabbit bone marrow mesenchymal stem cells with bacterial cellulose membrane," PeerJ, vol. 6, pp. e4656-e4656, 2018.

[140] Y. M. Cao, M. Y. Liu, Z. W. Xue et al., "Surface-structured bacterial cellulose loaded with hUSCs accelerate skin wound healing by promoting angiogenesis in rats," Biochemical and Biophysical Research Communications, vol. 516, pp. 1167-1174, 2019.

[141] G. Gainza, S. Villullas, J. L. Pedraz, R. M. Hernandez, and M. Igartua, "Advances in drug delivery systems (DDSs) to release growth factors for wound healing and skin regeneration," Biology and Medicine, vol. 11, no. 6, pp. 1551-1573, 2015.

[142] Y.-K. Lin, K.-H. Chen, K.-L. Ou, and M. Liu, "Effects of different extracellular matrices and growth factor immobilization on biodegradability and biocompatibility of macroporous bacterial cellulose," Journal of Bioactive and Compatible Polymers, vol. 26, pp. 508-518, 2011.

[143] B. Wang, X. Lv, S. Chen et al., "Use of heparinized bacterial cellulose based scaffold for improving angiogenesis in tissue regeneration," Carbohydrate Polymers, vol. 181, pp. 948956, 2018.

[144] P. Rørth, "Whence directionality: guidance mechanisms in solitary and collective cell migration," Developmental Cell, vol. 20, pp. 9-18, 2011.

[145] N. L. Occleston, A. D. Metcalfe, A. Boanas et al., "Therapeutic improvement of scarring: mechanisms of scarless and scarforming healing and approaches to the discovery of new treatments," Dermatology research and practice, vol. 2010, 10 pages, 2010.

[146] M. Jin, W. Chen, Z. Li, Y. Zhang, M. Zhang, and S. Chen, "Patterned bacterial cellulose wound dressing for hypertrophic scar inhibition behavior," Cellulose, vol. 25, pp. 67056717, 2018

[147] Y. Hu, H. Liu, X. Zhou et al., "Surface engineering of spongy bacterial cellulose via constructing crossed groove/column micropattern by low-energy CO2 laser photolithography toward scar-free wound healing," Materials Science and Engineering: C, vol. 99, pp. 333-343, 2019.

[148] J. Yu, T.-R. Huang, Z. H. Lim et al., "Production of hollow bacterial cellulose microspheres using microfluidics to form an injectable porous scaffold for wound healing," Advanced Healthcare Materials, vol. 5, pp. 2983-2992, 2016.
[149] L. P. Soares, M. G. D. Oliveira, A. L. B. Pinheiro, B. R. Fronza, and M. E. S. Maciel, "Effects of laser therapy on experimental wound healing using oxidized regenerated cellulose hemostat," Photomedicine and laser surgery, vol. 26, no. 1, pp. 10-13, 2008.

[150] M. Pandey, N. Mohamad, W.-L. Low, C. Martin, and M. C. I. M. Amin, "Microwaved bacterial cellulose-based hydrogel microparticles for the healing of partial thickness burn wounds," Drug delivery and translational research, vol. 7, pp. 89-99, 2017.

[151] P. Brassolatti, P. S. Bossini, H. W. Kido et al., "Photobiomodulation and bacterial cellulose membrane in the treatment of third-degree burns in rats," Journal of Tissue Viability, vol. 27, no. 4, pp. 249-256, 2018.

[152] S. Chen and Y. Huang, "Bacterial cellulose nanofibers decorated with phthalocyanine: Preparation, characterization and dye removal performance," Materials Letters, vol. 142, pp. 235-237, 2015.

[153] M. Safaei, M. Taran, M. M. Imani et al., "Application of Taguchi method in the optimization of synthesis of cellulose-MgO bionanocomposite as antibacterial agent," Polish Journal of Chemical Technology, vol. 21, 2019.

[154] S. Moritz, C. Wiegand, F. Wesarg et al., "Active wound dressings based on bacterial nanocellulose as drug delivery system for octenidine," International Journal of Pharmaceutics, vol. 471, no. 1-2, pp. 45-55, 2014.

[155] K. Cutting and M. Butcher, "DACC antimicrobial technology: a new paradigm in bioburden management," Journal of wound care, vol. 20, p. 1, 2011.

[156] M. Safaei, M. Taran, R. Rezaei et al., "Synthesis and anticancer properties of bacterial cellulose-magnesium oxide bionanocomposite," Current Issues in Pharmacy and Medical Sciences, vol. 32, pp. 29-33, 2019.

[157] A. Gupta, D. Keddie, V. Kannappan et al., "Production and characterisation of bacterial cellulose hydrogels loaded with curcumin encapsulated in cyclodextrins as wound dressings," European Polymer Journal, vol. 118, pp. 437-450, 2019.

[158] I. B. de Mattos, S. P. Nischwitz, A.-C. Tuca et al., "Delivery of antiseptic solutions by a bacterial cellulose wound dressing: uptake, release and antibacterial efficacy of octenidine and povidone-iodine," Burns, vol. 46, no. 4, pp. 918-927, 2020.

[159] C. Campano, A. Balea, A. Blanco, and C. Negro, "Enhancement of the fermentation process and properties of bacterial cellulose: a review," Cellulose, vol. 23, no. 1, pp. 57-91, 2016.

[160] F. Esa, S. M. Tasirin, and N. A. Rahman, "Overview of bacterial cellulose production and application," Agriculture and Agricultural Science Procedia, vol. 2, pp. 113-119, 2014.

[161] M. Ul-Islam, W. A. Khattak, M. W. Ullah, S. Khan, and J. K. Park, "Synthesis of regenerated bacterial cellulose-zinc oxide nanocomposite films for biomedical applications," Cellulose, vol. 21, no. 1, pp. 433-447, 2014.

[162] S. Khan, M. Ul-Islam, W. A. Khattak, M. W. Ullah, and J. K. Park, "Bacterial cellulose-titanium dioxide nanocomposites: nanostructural characteristics, antibacterial mechanism, and biocompatibility," Cellulose, vol. 22, pp. 565-579, 2015.

[163] A. Khalid, H. Ullah, M. Ul-Islam et al., "Bacterial cellulose$\mathrm{TiO} 2$ nanocomposites promote healing and tissue regeneration in burn mice model," RSC Advances, vol. 7, pp. 4766247668, 2017.

[164] S. Malmir, A. Karbalaei, M. Pourmadadi, J. Hamedi, F. Yazdian, and M. Navaee, "Antibacterial properties of a 
bacterial cellulose CQD-TiO2 nanocomposite," Carbohydrate Polymers, vol. 234, article 115835, 2020.

[165] X. Wen, Y. Zheng, J. Wu et al., "In vitro and in vivo investigation of bacterial cellulose dressing containing uniform silver sulfadiazine nanoparticles for burn wound healing," Progress in Natural Science: Materials International, vol. 25, pp. 197-203, 2015.

[166] J. Wu, Y. Zheng, X. Wen, Q. Lin, X. Chen, and Z. Wu, "Silver nanoparticle/bacterial cellulose gel membranes for antibacterial wound dressing: investigation in vitro and in vivo," Biomedical Materials, vol. 9, article 035005, 2014.

[167] L. Zhang, Y. Yu, S. Zheng, L. Zhong, and J. Xue, "Preparation and properties of conductive bacterial cellulose-based graphene oxide-silver nanoparticles antibacterial dressing," Carbohydrate Polymers, vol. 257, article 117671, 2021.

[168] Y. Li, Y. Tian, W. Zheng et al., "Composites of bacterial cellulose and small molecule-decorated gold nanoparticles for treating Gram-negative bacteria-infected wounds," Small, vol. 13, article 1700130, 2017.

[169] S. Ye, L. Jiang, J. Wu et al., "Flexible amoxicillin-grafted bacterial cellulose sponges for wound dressing: in vitro and in vivo evaluation," ACS Applied Materials \& Interfaces, vol. 10, no. 6, pp. 5862-5870, 2018.

[170] C. Wiegand, S. Moritz, N. Hessler et al., "Antimicrobial functionalization of bacterial nanocellulose by loading with polihexanide and povidone-iodine," Journal of Materials Science: Materials in Medicine, vol. 26, p. 245, 2015.

[171] F. Wahid, X.-J. Zhao, X.-Q. Zhao et al., "Fabrication of Bacterial Cellulose-Based Dressings for Promoting Infected Wound Healing," ACS Applied Materials \& Interfaces, vol. 13, pp. 32716-32728, 2021.

[172] M. E. Cam, M. Crabbe-Mann, H. Alenezi et al., "The comparision of glybenclamide and metformin-loaded bacterial cellulose/gelatin nanofibres produced by a portable electrohydrodynamic gun for diabetic wound healing," European Polymer Journal, vol. 134, article 109844, 2020.

[173] U. Beekmann, P. Zahel, B. Karl et al., "Modified bacterial cellulose dressings to treat inflammatory wounds," Nanomaterials, vol. 10, p. 2508, 2020.

[174] A. Futagami, M. Ishizaki, Y. Fukuda, S. Kawana, and N. Yamanaka, "Wound healing involves induction of cyclooxygenase- 2 expression in rat skin," Laboratory Investigation, vol. 82, pp. 1503-1513, 2002.

[175] P. Brassolatti, H. W. Kido, P. S. Bossini et al., "Bacterial cellulose membrane used as biological dressings on thirddegree burns in rats," Bio-medical materials and engineering, vol. 29, no. 1, pp. 29-42, 2018.

[176] N. Melnikova, A. Knyazev, V. Nikolskiy et al., "Wound healing composite materials of bacterial cellulose and zinc oxide nanoparticles with immobilized betulin diphosphate," Nanomaterials, vol. 11, p. 713, 2021.

[177] S. Napavichayanun, S. Ampawong, T. Harnsilpong, A. Angspatt, and P. Aramwit, "Inflammatory reaction, clinical efficacy, and safety of bacterial cellulose wound dressing containing silk sericin and polyhexamethylene biguanide for wound treatment," Archives of Dermatological Research, vol. 310, pp. 795-805, 2018.

[178] S. Napavichayanun, R. Yamdech, and P. Aramwit, "The safety and efficacy of bacterial nanocellulose wound dressing incorporating sericin and polyhexamethylene biguanide: in vitro, in vivo and clinical studies," Archives of Dermatological Research, vol. 308, pp. 123-132, 2016.

[179] W. Sajjad, T. Khan, M. Ul-Islam et al., "Development of modified montmorillonite-bacterial cellulose nanocomposites as a novel substitute for burn skin and tissue regeneration," Carbohydrate Polymers, vol. 206, pp. 548-556, 2019.

[180] B. Kumar, M. Vijayakumar, R. Govindarajan, and P. Pushpangadan, "Ethnopharmacological approaches to wound healing-Exploring medicinal plants of India," Journal of Ethnopharmacology, vol. 114, pp. 103-113, 2007.

[181] A. Picolotto, D. Pergher, G. P. Pereira et al., "Bacterial cellulose membrane associated with red propolis as phytomodulator: improved healing effects in experimental models of diabetes mellitus," Biomedicine \& Pharmacotherapy, vol. 112, article 108640, 2019.

[182] W. Sajjad, F. He, M. W. Ullah et al., "Fabrication of bacterial cellulose-curcumin nanocomposite as a novel dressing for partial thickness skin burn," Frontiers in bioengineering and biotechnology, vol. 8, 2020.

[183] M. Khamrai, S. L. Banerjee, S. Paul, S. Samanta, and P. P. Kundu, "Curcumin entrapped gelatin/ionically modified bacterial cellulose based self-healable hydrogel film: an ecofriendly sustainable synthesis method of wound healing patch," International Journal of Biological Macromolecules, vol. 122, pp. 940-953, 2019

[184] M. Khamrai, S. L. Banerjee, and P. P. Kundu, "Modified bacterial cellulose based self-healable polyeloctrolyte film for wound dressing application," Carbohydrate Polymers, vol. 174, pp. 580-590, 2017.

[185] A. Gupta, S. M. Briffa, S. Swingler et al., "Synthesis of silver nanoparticles using curcumin-cyclodextrins loaded into bacterial cellulose-based hydrogels for wound dressing applications," Biomacromolecules, vol. 21, pp. 1802-1811, 2020.

[186] E. Meng, C.-L. Chen, C.-C. Liu et al., "Bioapplications of bacterial cellulose polymers conjugated with resveratrol for epithelial defect regeneration," Polymers, vol. 11, p. 1048, 2019.

[187] P. Pourali and B. Yahyaei, "The healing property of a bioactive wound dressing prepared by the combination of bacterial cellulose (BC) and Zingiber officinale root aqueous extract in rats, 3," Biotech, vol. 9, p. 59, 2019.

[188] P. Fontes, S. Ribeiro, and A. Gaspar, "Bacterial cellulose/phytotherapic hydrogels as dressings for wound healing," Material science \& engineering international journal, vol. 3, pp. 162-173, 2019.

[189] A. Kefayat, R. Hamidi Farahani, M. Rafienia, E. Hazrati, and N. Hosseini Yekta, "Synthesis and characterization of cellulose nanofibers/chitosan/cinnamon extract wound dressing with significant antibacterial and wound healing properties," Journal of the Iranian Chemical Society, 2021.

[190] N. Mirmohammadsadegh, M. Shakoori, H. N. Moghaddam, R. Farhadi, A. R. Shahverdi, and M. Amin, "Wound healing and anti-inflammatory effects of bacterial cellulose coated with Pistacia atlantica fruit oil," DARU Journal of Pharmaceutical Sciences, 2021.

[191] Y. Qiu, L. Qiu, J. Cui, and Q. Wei, "Bacterial cellulose and bacterial cellulose-vaccarin membranes for wound healing," Materials Science and Engineering: C, vol. 59, pp. 303-309, 2016.

[192] N. Li, L. Yang, C. Pan et al., "Naturally-occurring bacterial cellulose-hyperbranched cationic polysaccharide derivative/ MMP-9 siRNA composite dressing for wound healing 
enhancement in diabetic rats," Acta Biomaterialia, vol. 102, pp. 298-314, 2020.

[193] T. Wild, M. Bruckner, M. Payrich, C. Schwarz, T. Eberlein, and A. Andriessen, "Eradication of methicillin-resistant Staphylococcus aureus in pressure ulcers comparing a polyhexanide-containing cellulose dressing with polyhexanide swabs in a prospective randomized study," Advances in skin \& wound care, vol. 25, pp. 17-22, 2012.

[194] G. F. Picheth, C. L. Pirich, M. R. Sierakowski et al., "Bacterial cellulose in biomedical applications: a review," International journal of biological macromolecules, vol. 104, pp. 97-106, 2017.

[195] A. Aboelnaga, M. Elmasry, O. A. Adly et al., "Microbial cellulose dressing compared with silver sulphadiazine for the treatment of partial thickness burns: a prospective, randomised, clinical trial," Burns, vol. 44, pp. 1982-1988, 2018.

[196] Z. Yang, R. Huang, B. Zheng et al., "Highly stretchable, adhesive, biocompatible, and antibacterial hydrogel dressings for wound healing," Advanced Science, vol. 8, article 2003627, 2021. 